\title{
Standardized ultrasonography with cine- loop documentation - diagnostic variability in liver and kidney examinations
}

\section{Carina Stenman}

Division of Radiological Sciences

Department of Medical and Health Sciences

Linköping University, Sweden 
CCarina Stenman 2016

Published articles has been reprinted with permission of the copyright holder.

Printed in Sweden by LiU-Tryck, Linköping, Sweden, 2016

ISBN: 978-91-7685-946-9

ISSN 0345-0082 
To Anders

Andreas and Mattias 


\section{CONTENTS}

Abstract

List of papers

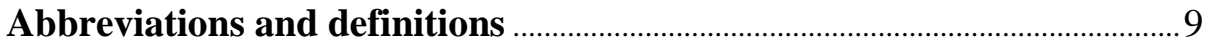

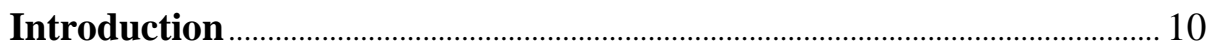

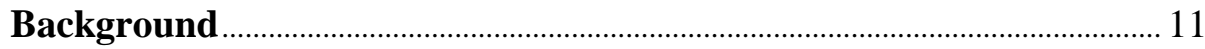

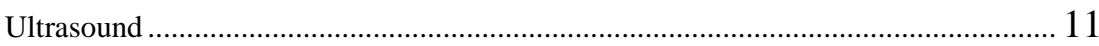

Contrast-enhanced ultrasound ……...................................................................... 15

Ultrasound and other modalities for imaging the kidneys and liver............................. 18

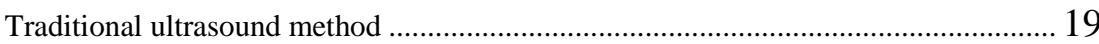

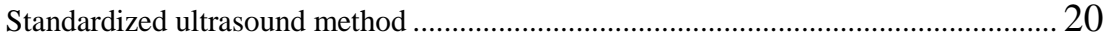

Examination of the kidneys with the standardized ultrasound method ......................... 22

Examination of the gallbladder with the standardized ultrasound method.................... 23

Examination of the liver with the standardized ultrasound method .............................. 24

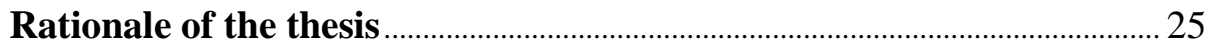

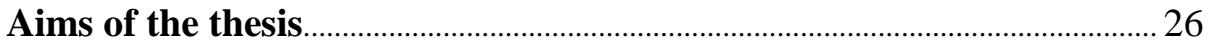

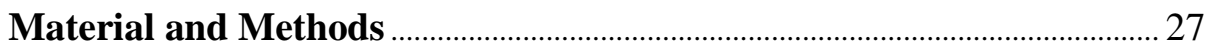

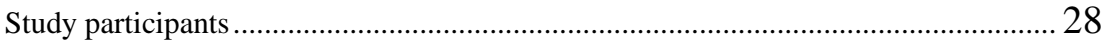

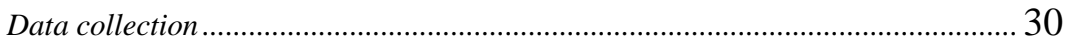

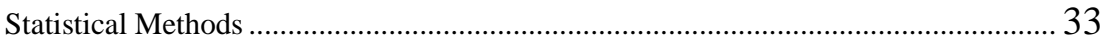

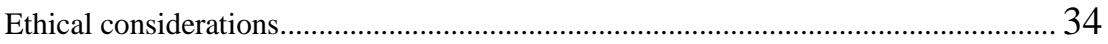

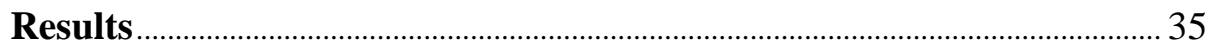

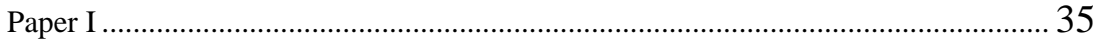

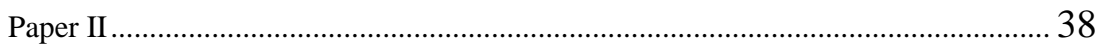

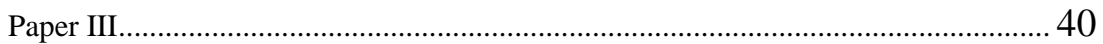

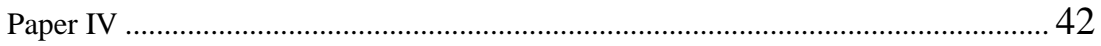




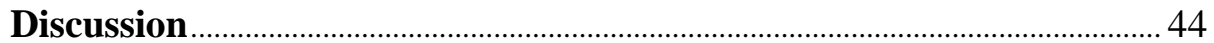

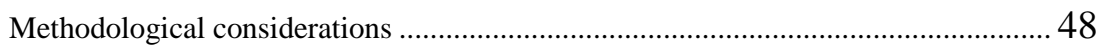

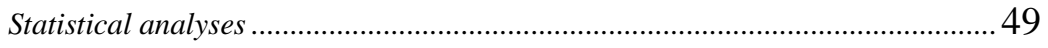

Generalizability ………………………………………………………..... 50

Topics for future research................................................................................................ 51

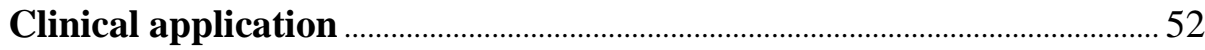

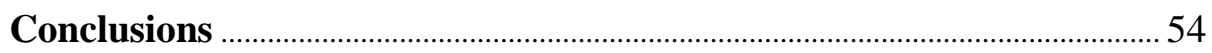

Svensk Sammanfattning …………………………………………………... 55

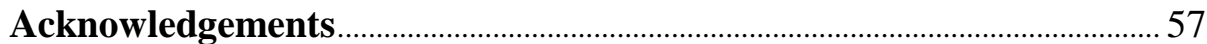

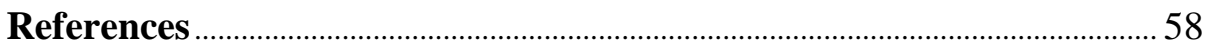




\section{ABSTRACT}

\section{Background}

Ultrasound examination of the abdomen is often a first choice at radiology departments due to the lack of ionizing radiation. For diagnostic accuracy and economic benefits there has been a need for new routines in this area that incorporate the benefits of an radiographer or sonographer performing a multitude of ultrasound examinations following strictly standardized examination protocols and documentation forms made by cine-loops that will give the radiologist access to all relevant information needed for an accurate post-examination diagnosis.

\section{Aim}

The overall objective of this thesis was to evaluate the diagnostic variability in examinations of the kidneys and liver that use a standardized ultrasound method along with video documentation of the entire examination and offline review by radiologists. More specifically, we wanted to compare the agreement between readers and between operators.

\section{Design and method}

This thesis is based on four quantitative studies using standardized protocols for kidney, liver and gallbladder examinations. In paper I, including 64 patients, and paper IV, including 98 patients, the patients were prospectively enrolled and the examinations were retrospectively reviewed. The patients in papers I and IV were examined by one radiographer (sonographer) and one radiologist during the same session. In paper I, findings using the standardized ultrasound method were compared with traditional bedside assessments by a radiologist. In paper IV, the patients were examined using only the standardized method. In paper II, including 98 patients, and in paper III, including 115 patients, the patients were examined by one sonographer using the standardized method and the examinations were reviewed by two or three radiologists.

\section{Results}

In paper I, no significant systematic differences were found between the findings using the standardized method and the traditional bedside assessment. 
Paper II showed good intra- and inter-observer agreement between three experienced radiologists when reviewing examinations conducted using the standardized method.

In paper III we verified good inter-observer agreement between two radiologists reviewing ultrasound examinations using the standardized technique in patients who had undergone surgery for colorectal cancer. Intravenous contrast was used and the injection of contrast medium increased the visibility of liver lesions.

In paper IV, we observed that using a standardized cine-loop technique, there was a slightly better inter-operator agreement than inter-reader agreement.

\section{Conclusion}

The satisfactory agreement shown in all four studies suggests that the new workflow method using standardized ultrasound examinations and stored cine-loops, performed by a radiographer or sonographer and analyzed offline by a radiologist, is a promising technique. The results are less affected when a radiologist examiner is replaced by a radiographer or sonographer than when the reviewer is replaced by a different radiologist.

Keywords Intra- and inter-observer agreement, standardized method, cineloop imaging, renal and liver sonography, ultrasound 


\section{LIST OF PAPERS}

This thesis consists of an introduction to a new standardized ultrasound workflow, and is based upon the following papers, which will be referred to in the text by their Roman numerals.

I. Carina Stenman, Lars Thorelius, Anders Knutsson, Örjan Smedby. Radiographer-acquired and radiologist-reviewed ultrasound examination agreement with radiologist's bedside evaluation. Acta Radiologica 2011; $52: 70-4$

II. Carina Stenman, Shazia Jamil, Lars Thorelius, Anders Knutsson, Örjan Smedby. Do radiologists agree on findings in radiographer-acquired ultrasound liver examinations? J ultrasound med. 2013; 32: 513-8.

III. Carina Stenman, Robert Glavas, Joachim Davidsson, Anders Knutsson, Örjan Smedby. Visualization of liver lesions in standardized video-documented ultrasonography - inter-observer agreement and effect of contrast injection. Med Ultrason. 2015; 17: 437-443.

IV. Carina Stenman, Robert Glavas, Ann-Lis Enlund, Kjell Jansson, Lars Thorelius, Örjan Smedby. Do radiologists agree when reviewing ultrasound examinations performed by a sonographer and a radiologist? (Submitted to Acta Radiologica) 


\section{ABBREVIATIONS AND DEFINITIONS}

B-mode

$\mathrm{CD}$

CEUS

Cine-loops

CT

(G) Gauge

HU

ICC

$\mathrm{MHz}$

MI

MPa

MRI

PACS

SD

Skip areas

SonoVue ${ }^{\circledR}$,

Syngo Dynamics

US

2D
Brightness mode

Color Doppler

Contrast-enhanced ultrasound

Sequence of individual frames

Computed tomography

A cannula outer diameter measured in units of gauge. $(20$ gauge $=0.8 \mathrm{~mm})$

Hounsfield Units

Intraclass correlation

Megahertz (common frequency for diagnostic ultrasound)

Mechanical Index

Megapascal

Magnetic resonance imaging

Picture archiving and communication system

Standard deviation

Small areas of less affected parenchyma in a liver with steatosis

Intravenous contrast agent (sulfur hexafluoride with a phospholipid shell)

PACS for ultrasound

Ultrasound

Two-dimensional 


\section{INTRODUCTION}

Ultrasound (US) imaging is an easy and widely available diagnostic technique used in clinical practice to evaluate patients, and is often the first choice for examining organs such as the kidneys, liver and gallbladder. US offer anatomical and functional information from a variety of tissues and organic systems. Compared to other medical imaging methods, US has several advantages such as lack of radiation, high availability and low cost, and in most applications it is a non-invasive method. It also provides images in real time, it is portable, and can be brought to the patient for bedside use. US is said to be observer-dependent and in general, the results of US examinations are presently regarded as subjective and highly dependent on the skill of the individual examiner (1-3).

The radiology department at the university hospital in Linköping, Sweden, uses a standardized method for US examinations. Examinations are performed by a radiologist or, in suitable cases, by a radiographer or a sonographer according to a strictly defined examination protocol with organ and structure standardized scanning patterns, and the entire examination is stored as cine-loops (4). Cine-loops are short films covering 5 - 10 centimeters in 5 - 10 seconds. One exception is for measurements that are preferably carried out with static images. The dynamic scans are stored in the ultrasound system and transferred to the Picture Archiving and Communication System (PACS) for US (Syngo Dynamics, Siemens Medical Systems), from where the cine-loops can be reviewed on a later occasion. With the standardized method, it is possible for radiographers to perform ultrasound examinations, while the diagnostic interpretation remains in the hands of the radiologists. In a situation in which ultrasound examinations are in great demand, this can help in handling availability problems for radiological services. The standardized method also facilitates comparisons between an old and a new examination of the same patient (5). A prerequisite for recommending the workflow strategy with standardized ultrasound examination protocols stored as cine-loops is that no diagnostic information is lost in the process (6). The clinical experience found in the literature from different areas where cine-loop documentation for US examinations has been used, has shown positive results (7-11). 


\section{BACKGROUND}

Abdominal US can be used to diagnose diseases in the internal organs such as in the kidneys and the liver $(7,12)$. The recent advances in image processing speed, and higher memory capability, have increased interest in sonographic examinations of the kidneys and other organs, and have led to a substantial increase in the use of US $(7,13)$. Problems when examining a patient with abdominal US can occur when a large amount of gas is present inside the bowels and/or if there is much abdominal fat. With obese patients it may be difficult to penetrate the fat layer and the examination quality may deteriorate with increasing depth due to the higher attenuation (14). When a large amount of gas is present inside the bowels it is important to examine the patient in different positions, such as left and right decubitus, or the prone position when necessary (5).

Contrast-enhanced ultrasonography (CEUS) has improved both the detection and characterization of focal liver lesions and has been shown to be an important imaging method, and plays a major role in distinguishing benign from malignant liver lesions (15-20). CEUS can be performed for a variety of indications on practically all parts of the human body $(21,22)$.

\section{ULTRASOUND}

US transmit high frequency sound waves from a transducer (Figure 1) and needs a physical medium like air, water, or tissue to support its propagation. A transducer is any device that converts energy from one form into another (23). The sound waves are emitted from piezoelectric crystals from the transducer and are fabricated from material that changes electrical signals to mechanical vibrations and changes mechanical vibrations to electrical signals (24). For diagnostic applications, medical ultrasound machines use pressure pulses with a frequency ranging between 1 and $15 \mathrm{MHz}(14,23$, $24)$. The examinations are commonly performed in real time and with the capacity to visualize several planes of the organs depending on the position of the transducer. 


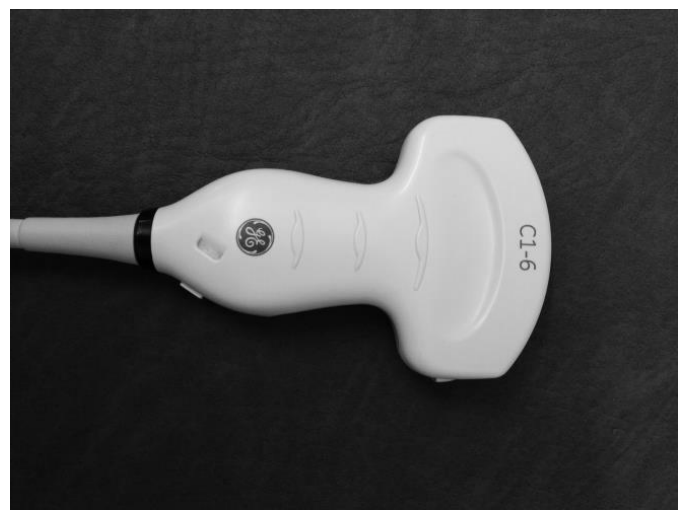

\section{Figure 1.}

A 1-6 MHz transducer, GE LOGIC e9 system (GE Healthcare, Medical Systems, Milwaukee, WI).

The physics and the technology involved in US imaging have an effect on how structures appear (24). The US image is created by first transmitting sound waves into the body and then detecting the intensity of the reflected echoes (Figure 2). As US waves pass through various body tissues, their intensity is reduced and they are reflected back to the transducer, creating an image on the ultrasound screen (24).

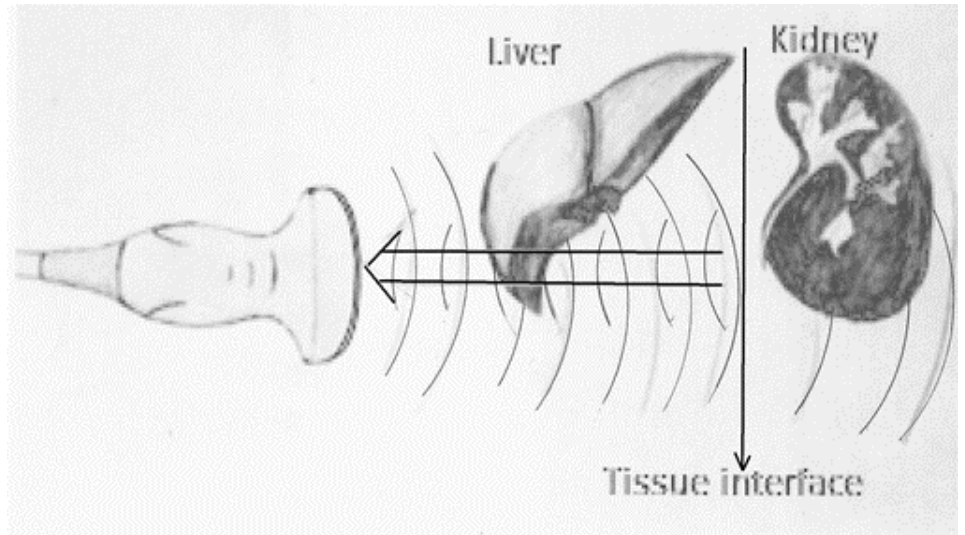

Figure 2.

An ultrasound beam reflects back to its source when it encounters an interface between different tissues or media. (illustration by L \& J Stenman)

Brightness mode (B-mode) is the basic mode that is commonly used in a variety of applications (23). The B-mode gives a two-dimensional (2D) gray scale image that represents the anatomical site of the slice (Figure 3). These 
thin slices are less than $1 \mathrm{~mm}$ each and can be sagittal, coronal, transverse or oblique (24).

B-mode is the basis for all gray scale imaging modalities developed (Mmode, 2D and 3D). The dynamic character of ultrasound scanning makes it important to have a good understanding of the processes. Increasing the transmitted frequency will improve the axial spatial resolution of the image, but the attenuation of ultrasound in tissues, i.e. the reduction in amplitude of the ultrasound as a function of distance due to scattering and absorption, is directly related to the frequency and is often expressed as signal loss, as $\mathrm{dB} / \mathrm{cm}$. Attenuation varies between different types of soft tissues and for most parts occurs in the range of about $0.3-0.8 \mathrm{~dB} / \mathrm{cm} / \mathrm{MHz}$ (23).

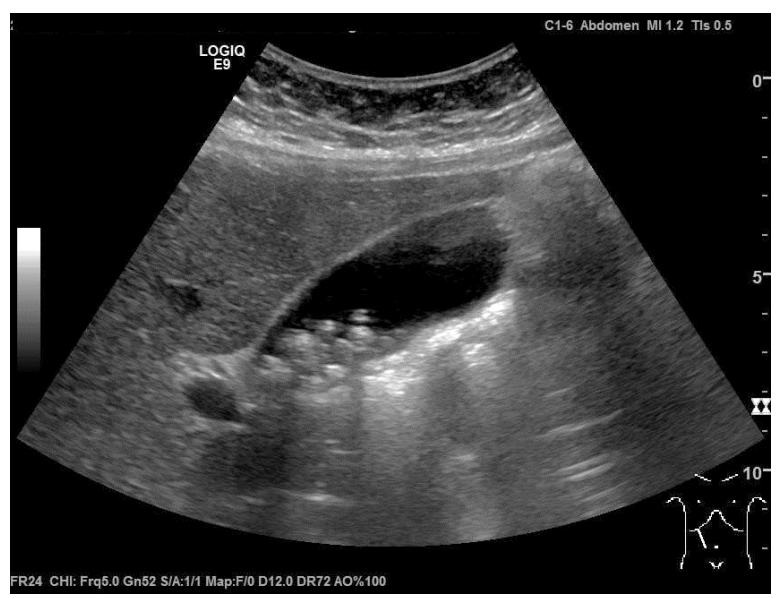

Figure 3

A $2 D$ gray scale image of the gallbladder with concrements.

Higher frequencies result in greater attenuation, and weaker amplitudes of the backscattered echoes. The operating frequency chosen is therefore always a compromise between high resolution and penetration depth. The speed of sound depends on the tissue type, and boundary surfaces between tissues function as partial or total reflectors of the ultrasound waves. It is commonly assumed to be $1540 \mathrm{~m} / \mathrm{s}$ for most diagnostic applications (23). Image quality is limited by total reflection by air- or gas- containing organs, skeletal or other calcified structures and by the depth of the object being examined. The high diagnostic exchange of this technology, along with its simple application has currently made it a routine method in daily medical practice. A regular US $2 \mathrm{D}$ grayscale examination use sound waves to produce images, but cannot show blood flow. Ordinary US is therefore often 
complemented with Doppler sonography, which is useful, e.g. to confirm that an unclear structure consists of a blood vessel (14).

The most common use of the color Doppler is to image the movement of blood through blood vessels and are an important tool in diagnostic US procedures (25) (Figure 4). This technique combines anatomical information with velocity information using ultrasonic Doppler techniques to generate color-coded maps of tissue velocity on grey-scale images of tissue anatomy (25).

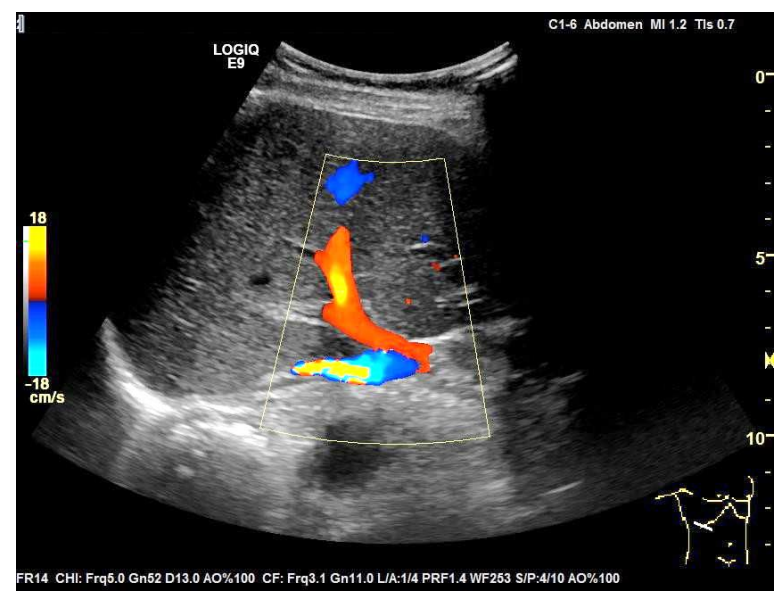

Figure 4.

Color Doppler ultrasound image. The allocated colors are often red for flow towards the transducer and blue for flow away from the transducer.

At present there are no known health risks associated with exposure to diagnostic US. For real time imaging with high spatial and temporal resolution, it is used for most areas of the body, and is thus one of the most widely used imaging modalities in medicine (23). However, diagnostic US is considered more operator-dependent than other modalities (24) and can therefore be further improved by standardized imaging protocols. 


\section{CONTRAST-ENHANCED ULTRASOUND}

Contrast enhanced ultrasound (CEUS) can contribute to a better identification and characterization of focal lesions in parenchymal organs (14).

The use of intravenous contrast was introduced to clinical practice at the beginning of the 1990s. Contrast enhancement improves the sensitivity of ultrasound (26). Current (second generation) forms of intravenous contrast that are approved and clinically used include SonoVue (Bracco SpA, Milan, Italy), Optison (GE Healthcare, Princeton, NJ), Definity (Lantheus Medical Imaging, N. Billerica, Mass), and Levovist (Schering AG, Berlin, Germany) (27). The contrast agents consist of microbubbles (approximately 1-8 $\mu \mathrm{m}$ ), generally filled with a perfluorinated gas that has a low solubility, and stabilized with a phospholipid or protein shell to improve circulation time. They are injected intravenously and serve as intravascular tracers $(27,28)$. This composition combination allows the agent to last for a certain period of time inside the blood vessel (21). After circulating for several minutes inside the blood vessel lumen the microbubbles dissolve, the internal gas is exhaled by the lungs and the coating shell is metabolized, mainly in the liver $(17,21)$. CEUS makes use of microbubble-based contrast agents to improve the echogenicity of blood and thus improve the visualization and assessment of large vessels and tissue vascularity as all bubble-specific echoes originate from the blood volume. When microbubbles interact with ultrasound waves, they change shape, contracting during the compression (high pressure) phase and expanding during the rarefaction (low pressure) phase. At lowintermediate acoustic pressure, these microbubble oscillations result in the formation of a non-linear signal containing harmonics of the transmitted fundamental frequency $(29,30)$.

The introduction of US contrast media in the last decade has increased the accuracy and application areas of ultrasound, e.g. in liver lesion detection and characterization, for differentiating benign from malignant lesions of the liver, especially where small lesions are undetected by CT or MRI $(31,32)$. Liver metastases can be detected during the portal and late phases, with a few exceptions (16). The contrast can be used to aid diagnosis of primary and metastatic tumors in the liver and other types of disease. CEUS has one of its most important applications in liver imaging (33). At the university hospital in Linköping intravenous contrast agents are used frequently with approximately 8700 CEUS are conducted each year. 
US contrast agents offer high sensitivity, with the ability to visualize the flow of a single bubble (Figure 5).
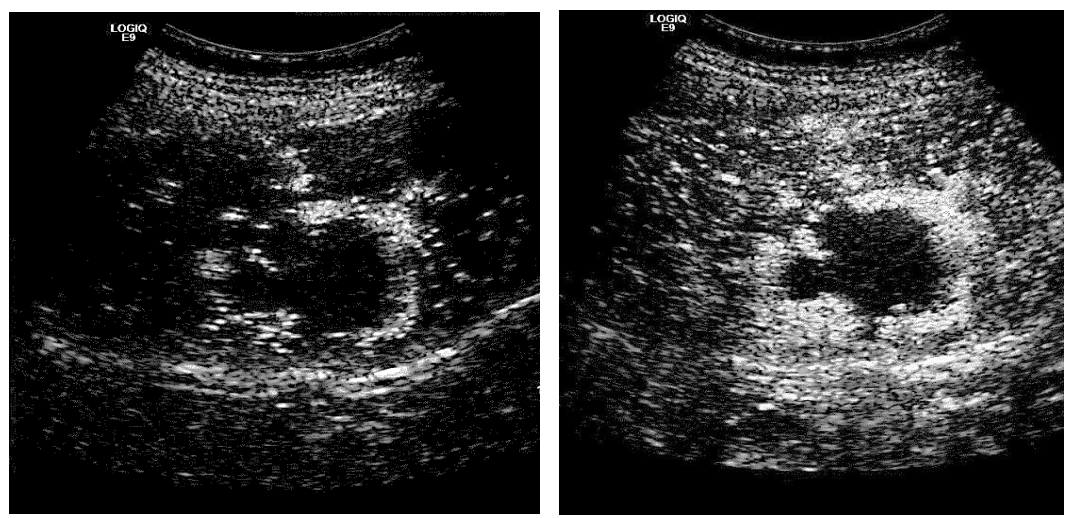

Figure 5

Ultrasound images after intravenous contrast injection. The image to the left shows the first contrast bubbles as small dots after 25 seconds in a hemangioma, the image to the right after 29 seconds.

The contrast agents used in US are not nephrotoxic, they are non-toxic and small enough to pass through the pulmonary system and recirculate for several minutes $(17,28)$. They are very simple to use, well tolerated by the patients and can be safely used in renal impairment unlike computed tomography $(\mathrm{CT})$ and magnetic resonance (MR) contrast agents. In very rare cases, severe adverse events including anaphylactic reactions in less than one out of 10,000 patients have been reported (34). Previous studies have shown that the diagnostic ability of CEUS could be compared with contrast CT and contrast MRI regarding characterization of focal liver lesions $(35,36)$.

Liver metastases have characteristic features in all three phases and are usually classified into arterial (8-30 s from contrast agent injection), portal (31-120 s), and late (121-360 s) phases $(16,17)$. Figure 6 shows the three phases in a normal liver parenchyma. The late phase is the most important for distinguishing benign from malignant lesions, the hypo vascularization in this phase being the most specific sign of malignancy $(17,18)$. 


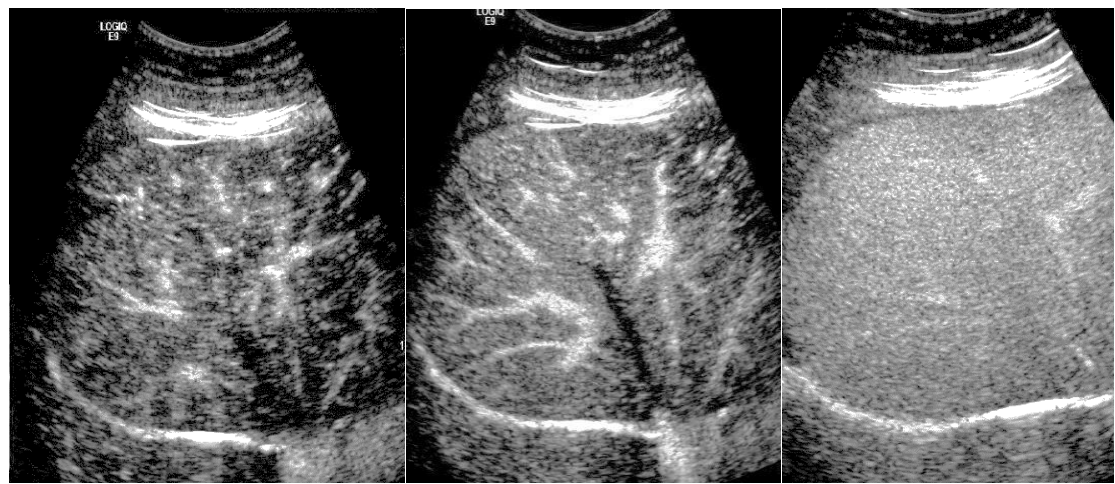

Figure 6.

The three vascular phases in a normal liver parenchyma. The images from left to right, the arterial, portal and the late phase.

The ultrasound machine settings play an important role when using a contrast agent consisting of microbubbles. The mechanical index (MI) is the operator's most important indication of the expected behavior of the contrast agent bubbles. For CEUS a low mechanical-index is mandatory since microbubbles can be destroyed when subjected to high acoustic pressures $(28,29)$. The MI settings can be defined in physical terms as, $M I=P_{n e g} / \sqrt{f}$, where $P_{\text {neg }}$ is the peak rarefaction pressure in $\mathrm{MPa}$, and $f$ is the frequency in $\mathrm{MHz}$.

MI is an estimate of the maximum of the amplitude of the pressure pulse in tissue, reflecting the power of the system. In very simple terms, higher MI tends to correspond to higher acoustic pressure emission and consequently to more rapid disruption of microbubbles (16). The MI settings depend on different things such as the distance from the transducer, the degree of steatosis, examination time, lesion circulation speed etc. (5).

The contrast agent is administered as a bolus injection within 2 seconds followed by flushing with saline, ideally to minimize and avoid destruction of the microbubbles during their injection, it is recommended to use an intravenous line not smaller than $20 \mathrm{G}(0.8 \mathrm{~mm})(17)$. 


\section{ULTRASOUND AND OTHER MODALITIES FOR IMAGING THE KIDNEYS AND LIVER}

Different diagnostic imaging techniques that are commonly used in radiology departments today when examining the abdomen are computed tomography (CT), magnetic resonance imaging (MRI) and ultrasonography (US). These imaging techniques have gained widespread acceptance in several fields of medicine (37). The preferred method to be used depends on local equipment, availability and operator expertise (13).

An advantage of CT is its ability to quantitatively measure the attenuation in different tissues. CT is based on the principle that the density of the tissue passed through by the X-ray beam can be measured by calculation of the attenuation coefficient (37). The attenuation is measured in Hounsfield Units (HU). Water has a value of $0 \mathrm{HU}$, air is $-1000 \mathrm{HU}$, and bone is up to around $+1000 \mathrm{HU}$ (14). CT is widely available in many parts of the world and is often the first choice for examining the abdomen with a focus on malignancies (14). This technique has the advantage of being fast and sensitive when gas is present inside the bowels, and it can give a good representation of all abdominal organs (14). Modern CT equipment combined with a contrast medium provides a reliable imaging method with high spatial resolution in several phases of vessel enhancement enabling imaging of the liver in 1-2 arterial phases, the portal venous phase and later phases if needed to distinguish benign from malignant liver lesions $(20,38)$. The kidneys are easy to examine, identify and define with a CT examination. Complete examination of the kidneys is performed by taking images both before and after administration of intravenous contrast (14). A disadvantage of CT is the ionization radiation. CT is today the largest single source of ionization radiation exposure to the population in medicine (39).

MRI is an imaging technique used primarily in medical settings to produce high quality images of the inside of the human body. MRI is based on the electromagnetic interactions of the hydrogen nuclei (protons) in the body and corresponds to the distribution of protons and differences in their relaxation times. The hydrogen nucleus is the smallest atomic nucleus and because of the body's considerable water content this means that we have a large number of "magnets" inside us (14). All protons exhibit magnetic properties due to their electrical charge and spin. The imaging process can be tuned to display different tissues in many ways, with varying contrast, highlighting, and 
structures. MRI is a non-invasive technique for revealing the internal structure and function of the liver and kidneys in the human body and does not involve ionization radiation (40). Despite considerable improvements in imaging quality and speed, the underlying technology remains unchanged compared to the first generation scanners that emerged on the market 30 years ago (40). MRI is generally not used as the primary method for examining the kidneys, mainly because of the limited availability and higher cost than other methods such as CT and ultrasound. Both MRI and CT are sensitive to motion artifacts (14).

Due to recent technological advances in image quality for US, it is frequently used to assess liver disease including hepatomegaly and steatosis, and for diagnosing focal liver lesions. Steatosis is a condition, characterized by increased fat content in the liver, which may progress to fibrosis and cirrhosis. The US evaluation is based mainly on the visual impression of the liver echogenicity and posterior attenuation of the US beam $(2,3)$. It has been shown that there is a need for a more objective method to grade steatosis in the liver (2). US plays an major role in the imaging of conditions and procedures common in patients with diffuse hepatic disease (41). US may be helpful in detecting cysts, tumors, obstructions, abscesses, fluid collection, stones or infection in the kidneys, and is also used to determine the size, shape and location of them. However, US provides no information about renal function (14). US has its place in many diseases because it has high diagnostic accuracy, is painless and can be performed when there is poor kidney function. Medical questions like hydronephrosis are answered with high degree of safety (14). In addition to the morphological diagnosis, US measurements of kidney volume and size considered to be reliable predictors of renal function in patients with chronic renal disease (42).

\section{TRADITIONAL ULTRASOUND METHOD}

The method currently used in most European countries will be called the traditional method in this thesis. An US examination using the traditional method is usually performed in a systematic way. The documentation of an examination of a patient consists of storing selected static images in the PACS. Reviewing the images from a traditional US method has limited value. Some review can be made if moving sequences are saved (14). According to Pallan et al. (43), the value of reviewing static US images is very limited and is associated with lower diagnostic specificity $(7,8)$. 
In a previous study they say, when looking at static images, the dynamic aspect is lost and some pathology can be misinterpreted (44).

When using the traditional technique, with static images, the examiner should always be the one who writes the report.

This method is performed by the radiologist or, sometimes in suitable cases, a trained sonographer and the report is written with the support of static images and memory. The traditional method offers no review of an entire organ or area of interest. In cases when reevaluation is needed, when a new clinical question arises after the examination, and the examination is made by a sonographer it is important to follow strict protocols and have open communication between sonographer and radiologists to avoid mistakes, it is rarely helpful to reevaluate the static images $(44,45)$. Experience and training in ultrasound imaging has great importance when using the traditional method (46). Although the patient may have been examined in a systematic way, only the examiner knows what was seen before and after the static images stored in the PACS. Therefore, this is usually considered as an operator-dependent method. In general, the results of traditional ultrasound examinations are regarded as subjective and highly dependent on the skill of the individual examiner (44, 45, 47). A study by Faschingbauer et al. compared the diagnostic performance in a group of examiners with four different levels of experience in gynecological US. Their study showed that interpretation of static US images significantly improved with an increasing level of experience (48).

\section{STANDARDIZED ULTRASOUND METHOD}

In a few Swedish hospitals and in one hospital in Norway an alternative approach to conducting US examinations has been introduced. The approach is to use an examination protocol and capture the entire organ or area of interest in a series of cine-loops with the ability to review the entire examination at a workstation. This US method means, among other things, that dynamic films, so called cine-loops covering the entire examination, are stored in the PACS. Cine-loops are short films, and the speed of scanning is approximately 5-10 $\mathrm{cm}$ in 5-10 seconds (5). Filming takes place over 5-10 seconds so that no pathology will be missed. The method makes it possible to review and recheck an organ or area of interest (5). When using a standardized examination protocol, regardless of who carried out the previous examination - a radiologist, radiographer or sonographer - it is easy to review in parallel an old and a new examination of the same patient. 
Scanning is always done with a longitudinal sweep from left to right and a transverse sweep from superior to inferior, regardless of whether the patient is lying on his left or right side or in a prone position. The scanning speed or direction should not be changed in the cine-loop during the scanning if unexpected pathology appears. Whole areas or organs are scanned with a good margin, scanning starts outside and ends outside the organ or area of interest. Additional cine-loops are taken if needed. For optimum production of ultrasound examinations and cine-loops, ultrasound parameters such as gain adjustment, focal zone locations and depth have to be changed on a case-by-case basis throughout the examination. Examination protocols summarize information, describing how different organs can be examined in a systematic way. It is also possible to see what patient position is recommended to easily visualize the organs (5).

A body marker indicating the position of the transducer is used on the ultrasound machine's monitor, which means that the reviewing radiologist has the opportunity to see where and how the examiner has placed the ultrasound transducer in relation to the patient's body. The marker for the transducer on the ultrasound machine's monitor can be rotated to the position in which the examiner has pointed the transducer on the patient's body (Figure 7). It is also possible to see what position the patient was in at the time of the examination. The cine-loops are stored in a dedicated PACS (Syngo Dynamics, Siemens Medical Systems), which is designed for the storage of cine-loops. From this PACS, cine-loops can be played at an appropriate speed at the workstation, and slow motion can be used to take a closer look.

It is also possible to stop the film for measurements. In the examination protocol, there is information on which transducer and frequency is suitable for the examination (5). Still images taken with the standard method are only used to illustrate measurements.
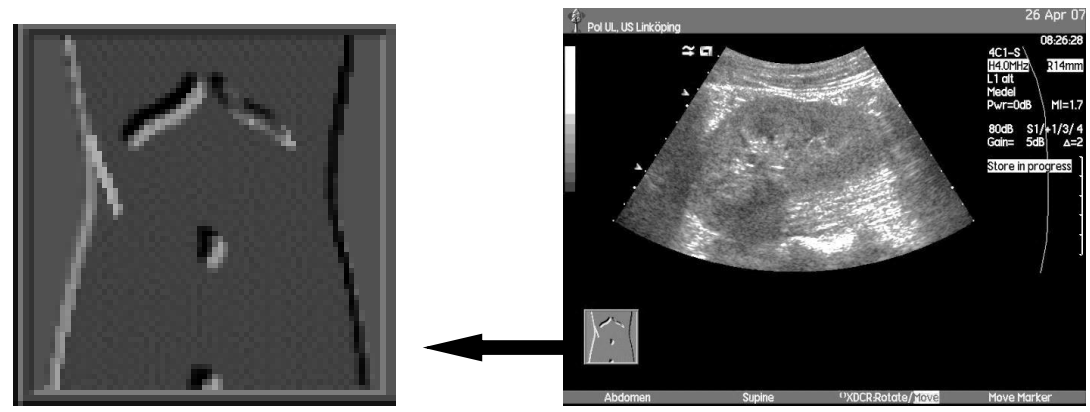

Figure 7.

A body marker indicating where and how the examiner has pointed the transducer on the patient's body. 
A central issue concerning the standardized method is to learn the technique of filming an organ or area of interest. For the examiner, it is important to produce images and cine-loops of high quality in order to enable the reviewer to make a correct diagnosis of the patient.

\section{EXAMINATION OF THE KIDNEYS WITH THE STANDARDIZED ULTRASOUND METHOD}

There are many normal variations in the anatomical structure of the kidneys. Both kidneys are scanned, for comparison and correlation with the patient's clinical history, always in two planes, longitudinally and transversally in both the supine and side positions. For the purpose of standardization and when there are two objects or organs, as with the kidneys, the examination starts with the left side.

The examination is conducted in two planes and two positions since pathology may be shown in one position but not the other. The kidneys are first scanned longitudinally since they are most naturally approached longitudinally (5). Cine-loops of the kidneys are carried out longitudinally from left to right and transversely, from top to bottom. For measurement of renal size, the longitudinal measurement is made and kept as a static image, which is especially important when e.g. measuring the kidney size in small children. The examination of the kidneys includes the urinary bladder, which is also filmed longitudinally and transversely. Examination of the kidneys and urinary bladder includes about ten cine-loops. When needed additional cine-loops are recorded, depending on the patient's anatomy or the possibility for the patient to cooperate. Throughout the scan, to prevent movement of the kidneys the patient is asked to take a deep breath and hold it, if possible. For the best results, the urinary bladder has to be full for optimally visualizing the bladder. Prior to the examination, the patient receives information about the examination in the mail. The patients do not need to fast prior to the examination of the kidneys. 
Example of an examination protocol of the kidneys (5).

1. Supine position, intercostal scan plane longitudinally along the left kidney, one Sonoscan.

2. Supine position, scan plane transversal or almost transversal to the left kidney, one Sonoscan.

3. Right decubitus position, most often inspiration, scan plane longitudinally along the left kidney, one Sonoscan,

4. Right decubitus position, most often inspiration, scan plane transversal or almost transversal to the left kidney, one Sonoscan.

5. Repeat 1-4 on the right kidney.

6. Transversal Sonoscan of urinary bladder.

7. Longitudinal Sonoscan of urinary bladder.

\section{EXAMINATION OF THE GALLBLADDER WITH THE STANDARDIZED ULTRASOUND METHOD}

The normal gallbladder is located on the visceral surface of the liver between the quadrate and right liver lobe, but this may vary greatly between individuals. The neck is especially difficult to visualize with US. Therefore, cine-loops of the lateral segments of the left liver lobe and the head of the pancreas are included in the examination for evaluation (5).

Patients are first examined in the supine position. The gallbladder should always be examined in two planes, as with any other organ in the body. Thereafter, the patient is placed in the left lateral position and filmed transversely and longitudinally towards the gallbladder. This is done to move the duodenum and reduce the negative effect of duodenal air. Examination of the gallbladder includes about ten cine-loops. The patients need to fast for six hours prior to the examination, to optimally visualize the gallbladder. Optimum conditions for the ultrasound examination are a fluid-filled gallbladder and as little gas in the gastrointestinal tract as possible (49). 


\section{EXAMINATION OF THE LIVER WITH THE STANDARDIZED ULTRASOUND METHOD}

The liver is the largest gland of the body. It is of irregular shape, weighs from 1 to $2 \mathrm{~kg}$ and is divided into eight segments (figure 8) (50). The ultrasound examination should cover the entire liver and define in which segment the pathology is located. The examination of the liver and biliary system includes a standard number of 11 cine-loops. In the transverse cine-loops, the entire liver is covered in the cranio-caudal direction with some margin. Some sweeps may consist of more than one cine-loop due to liver size (5). The patient is located in both the supine and the left lateral positions to allow the best visualization of the liver. For segments 2 and 3 the patient should be located in the supine position, and for segments 1 and $4-8$, in the left decubitus position (5). For each scan the patient is asked to take a deep breath and hold the breath throughout out the scan to allow visualization of the liver which can be located high up under the right costal arch. The gallbladder is also included in the examination of the liver. The patient needs to fast for six hours prior to the examination, to optimally visualize the gallbladder and liver. Similar as for the gallbladder examination, optimum conditions for the ultrasound examination are a fluid-filled gallbladder and as little gas in the gastrointestinal tract as possible (49).

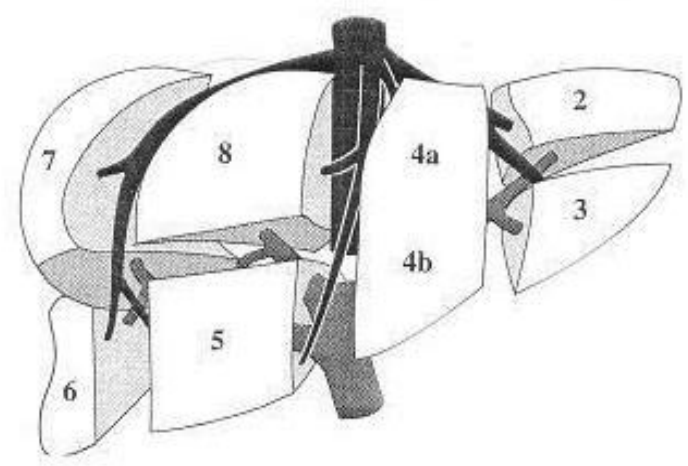

\section{Figure 8}

The segmentation of the liver according to Couinaud (1957) (51). 


\section{RATIONALE OF THE THESIS}

The central theme of this thesis is to present and evaluate a new workflow method with a standardized technique for clinical practice. The increasing number of patients referred to US examination, due to, among other things, its availability, low cost and absence of ionizing radiation may result in capacity problems and long waiting times for patients. Currently US examinations used at different hospitals most commonly use a method in which the examination is performed by the reader, who is usually a doctor. Static images are stored in a PACS and the opportunity to re-evaluate the ultrasound examination at a later point is almost impossible.

There is a need for radiologists to concentrate on more advanced or acute examinations. One approach is to let the radiographer or sonographer perform the less complicated examinations. With the use of a standardized technique, when re-evaluation by someone who did not conduct the examination is possible, this could help to solve the capacity problems, provided that the diagnostic quality is not degraded. 


\section{AIMS OF THE THESIS}

The overall aim of this thesis was to evaluate the introduced standardized US method that is used at the radiology department in Linköping, with special consideration of reproducibility in examinations of the liver and kidneys.

\section{Specific aims}

I. To compare the findings obtained by a traditional method of ultrasound examination by a radiologist and the standardized method in which a radiographer makes the examination, which can be reviewed later by the radiologist.

II. To evaluate the intra-observer and inter-observer agreement of sonographic liver examinations using strictly standardized examination protocols with cine-loop documentation.

III. To study the inter-observer agreement and effect of contrast injection on the visibility of liver lesions among radiologists reviewing ultrasound examinations acquired by a sonographer using a standardized examination protocol.

IV. To study the diagnostic variability in standardized ultrasound examinations of the kidneys by comparing inter-reader agreement between two radiologists reviewing examinations made by a sonographer and a radiologist, and inter-operator agreement between the sonographer and the radiologist. 


\section{MATERIAL AND METHODS}

This thesis is based on four quantitative studies. The four studies included outpatients referred to the radiology department in Linköping for an US examination of the kidneys, or the liver and gallbladder. A retrospective review of the US examinations was performed. For papers I and IV, the patients were prospectively enrolled and was reviewed retrospectively. The examinations, from the four studies, were stored in the dedicated PACS (Syngo Dynamics, Siemens Medical Systems, Erlangen, Germany). For papers I, II, III, sonograms were obtained with the US equipment, ACUSON Sequoia, Figure 9 a, (Siemens Medical Systems, Erlangen, Germany) using $4 \mathrm{C} 1$ and $6 \mathrm{C} 2$ convex transducers, of 1 to $6 \mathrm{MHz}$. For study IV, the GE LOGIC e9 system, Figure 9 b, (GE Healthcare, Medical Systems, Milwaukee, WI), using a convex transducer C1-6, of 1 to $6 \mathrm{MHz}$ was used.

(a)

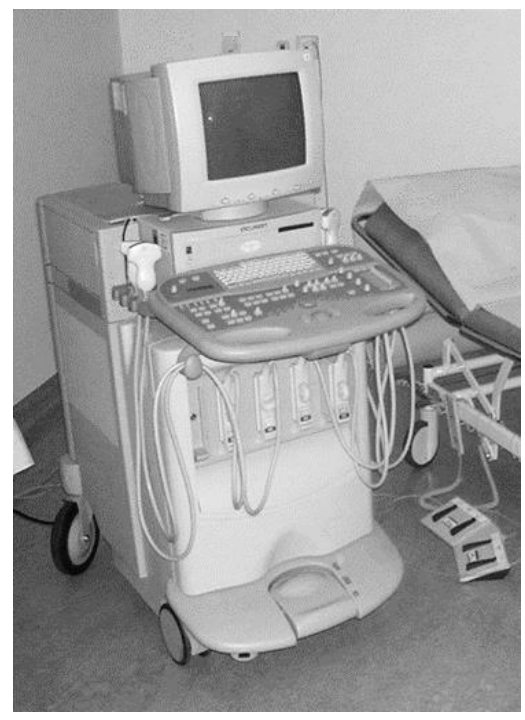

(b)

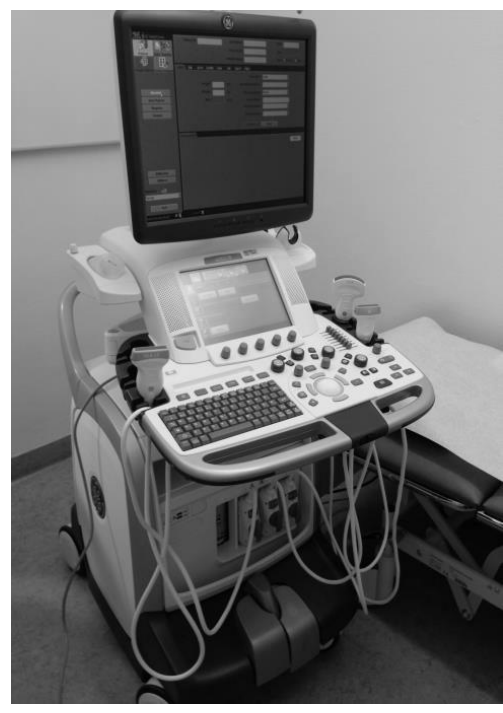

\section{Figure 9}

Image of two ultrasound systems, (a) ACUSON Sequoia (Siemens Medical Systems, Erlangen, Germany), (b) GE LOGIC e9 system (GE Healthcare, Medical Systems, Milwaukee, WI). 


\section{STUDY PARTICIPANTS}

The patients in the four studies were adult outpatients from 18 to 93 years and were considered in advance by the radiologists at the US section at the university hospital in Linköping as suitable to be examined by a radiographer or sonographer. Referring physicians in the four studies had chosen US as a first choice and had sent the referral to the radiology department. Referrals had targeted issues and the clinical question could be for kidney examinations, concrements, hydronephrosis and tumors. For liver and gallbladder examinations the clinical question could be tumor, concrements and steatosis. For an examination to be conducted by a radiographer or sonographer the patient had to be policlinic and have a targeted issue.

Paper I studied a total of 64 adult patients who were prospectively enrolled between October and December 2006 for clinical abdominal US at the radiology department, of the 64 patients, 30 were men and 34 were women. The age range was 19 - 93 years (median 60 years). In 27 cases, the kidneys were examined, and in 37 cases, the gallbladder was examined. The patients were examined by one radiographer and one radiologist during the same session. The radiologist examined the patients using a traditional method and the radiographer examined the patients using the standardized method. The standardized examinations were reviewed by two radiologists with experience from radiological US ranging from 12 to 17 years. Both radiologists were used to the standardized ultrasound method and reviewing ultrasound examinations made by someone else. The radiographer had worked with the standardized method for two years.

In paper II 98 adult patients were referred for clinical abdominal ultrasound of the liver at the radiology department, from 2006 to 2008. Of the 98 patients, 38 were men and 60 were women. The age range was $18-93$ years (median 56 years). The patients included in this study were referred to the radiology department for an US examination of the abdomen with a clinical question e.g. concerning concrements in the gallbladder, dilated bile ducts, focal changes, echogenicity of the liver or liver size. Three radiologists with varying length of US experience participated in the review of the examinations. Two had been working with US for about 15- 20 years and were used to reviewing cine-loops from US examinations in a workstation made by someone else. The third radiologist had been working with US for 10 years, but not in the same hospital, and not with this method. She was 
introduced to the technique two weeks before the start of the study. The radiologists reviewed the examinations at two different time points, with a four-week interval. The examinations were performed by one radiographer who had 2 years of experience from the standardized ultrasound method, when the study started.

In paper III, a retrospective review was performed of 115 US examinations of the liver before and after an intravenous contrast injection, performed from January 2008 and December 2012, by a sonographer who had, when the study started, 4 years of experience of the standardized technique with ultrasound. The patients were 62 males and 53 females, mean age 73, range 46-93 years old. The patients included in the study had undergone surgery for colorectal cancer. According to the clinical routine at the hospital in Linköping, CEUS is performed from six months to three years after surgery, at six-month intervals, to evaluate the liver and the clinical question of metastases. In the current study, the material that was collected, consisted of all patients who came for the two-year follow-up. The examinations were reviewed by two radiologists. They had 8-20 years of experience of abdominal ultrasound.

In paper IV, the study population consisted of 98 adult patients, aged from 18 to 92 , mean age 55, referred for diagnostic renal sonographic examination, who were prospectively enrolled from November 2012 to September 2014. All patients were examined by two examiners during the same session. The examiners were one radiologist and one sonographer who had when the study started 4-7 years of experience working with US and using the standardized method. The examinations were reviewed by two radiologists who were not employed at the hospital at which the study was performed but at two different hospitals in Sweden. The radiologists had access to the dedicated PACS where the ultrasound examinations were stored, and they could review the ultrasound examinations at their own hospitals. They had worked with ultrasound for 15 years and were used to work with the standardized technique. 


\section{DATA COLLECTION}

In the four studies, data collection was made by examining patients with the standardized ultrasound method, with one exception, in study I there was also a traditional method for US examinations, with diagnostic assessment in immediate connection with the examination. In studies II, III and IV the examinations made by a radiographer/sonographer or radiologist were reviewed by two or three radiologists.

The radiologists who reviewed the examinations at the workstations (Figure 10) had no access to clinical information about the patient. All examinations were stored in a dedicated PACS (Syngo Dynamics, Siemens Medical Systems, Erlangen, Germany.

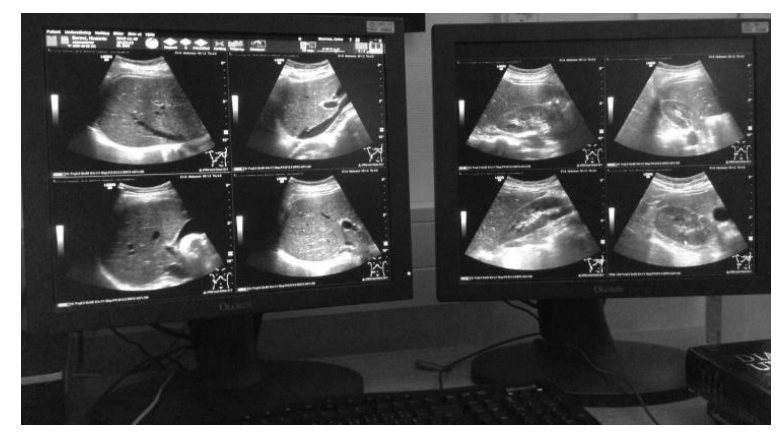

Figure 10

A workstation from were ultrasound examinations can be reviewed.

\section{Paper I}

The patients were examined by one radiographer and one radiologist during the same visit. The clinical question concerned e.g. for kidneys, hydronephrosis or tumor, and for the gallbladder, polyps or concrements. The two radiologists participating in the study were familiar with the two methods and the radiographer had worked with US for two years and had only used the standardized method. The radiographer performed the standardized examination of the patient, where cine-loops of 5-10 seconds were stored in the PACS. All data were acquired by the same radiographer, using a scanning protocol for the gallbladder and kidneys. The radiologist examined the same patient in the traditional manner and saved static images in the PACS over the area where any pathology or other finding was noted. The radiologist who examined the patient with the traditional method was 
never the same as the one who reviewed the standardized examination made by the radiographer.

Predetermined protocols were filled in. The protocols included options of common findings that can be detected in an US examination of the kidneys or gallbladder. For the kidneys, it contained various options such as cortical thickness (normal or decreased), hydronephrosis (presence or absence, judged visually), echogenicity (normal or increased, judged visually) and tumor (presence or absence). Furthermore, it included the number of cysts and the size of these. The size of the kidneys was also noted.

Regarding the examination of the gallbladder, the protocol included wall thickness (thin or increased), concrements (number and size), number and size of polyps, and other findings. The protocols for kidneys and gallbladder examinations were filled out by the radiologist immediately after examining the patient with the traditional method and when reviewing the standardized examination carried out by the radiographer, and a comparison was made of the two forms. The radiologist wrote the report and signed out the patient to avoid delay for clinical purposes.

\section{Paper II}

The review was made by three radiologists. All examinations were made by one radiographer, using the standardized ultrasound method. The examination of the liver contained about 11 cine-loops (5). In connection with the examination, the radiologists filled in a predetermined protocol containing various options concerning pathology that can be detected in an ultrasound examination of the liver. The various options were: echogenicity (normal, slightly increased, moderately increased or greatly increased), skip areas (yes / no) (52), parenchyma (regular or irregular), focal changes (yes or no, if yes: cyst, or other), number of focal changes $(1-\geq 5)$, diameter of the main focal changes $(\mathrm{mm})$, assessment of liver size (normal, large or small), gall bladder wall thickness (normal or thickened), concrement of the gallbladder (yes or no), polyps of the gallbladder (yes or no) and biliary

obstruction (yes or no). The radiologists also indicated in the protocol if they found a need for a complementary examination such as CT or MRI. Then the forms were compared for intra-observer and inter-observer agreement. After an interval of four weeks, when the examinations had been randomly rearranged, the review was performed again. The protocols were compared as before and the three radiologists were blinded to the initial reading. 


\section{Paper III}

Patients included in the study had undergone surgery for colorectal cancer, with a clinical question concerning metastases. A retrospective review was performed of 115 ultrasound examinations of the liver before and after a contrast injection. All data were acquired by the same sonographer, using a scanning protocol for the liver and biliary system consisting of approximately 7 to 11 cine-loops. The dynamic films were stored and transferred to a dedicated PACS. First, the liver was examined without the intravenous contrast agent, using the standardized ultrasound method. After the injection of the contrast agent $(2.4 \mathrm{ml}$ of SonoVue, Bracco, Italy) via a 20 -gauge intravenous catheter placed in a vein and followed by $5-10 \mathrm{ml}$ saline flush, the examination was repeated by the same sonographer beginning 90 seconds from the start of the injection, in the portal and late phase. If a focal lesion was seen before the contrast injection, the acquisition with contrast was used for characterization of the lesion in the arterial phase. After each review, the radiologists filled out an evaluation form including corresponding data before and after the intravenous contrast. The findings recorded included whether the examination was of diagnostic value or not, focal liver lesions (classified as cyst, metastases and other focal lesions), localization (Couinaud segments) (51) and the number and sizes of the focal liver lesions. The forms were compared for inter-observer agreement.

\section{Paper IV}

The 98 adult patients, aged from 18 to 92 , who had been referred for a diagnostic renal sonographic examination and were prospectively enrolled. Each patient was examined by one sonographer and one radiologist during the same session using the same machine and with the use of the standardized US method. All examinations were reviewed by two different radiologists. The radiologists were not working at the hospital where the study was carried out but they had access to the dedicated PACS at their own hospital, where all cine-loops were stored. After each reviewed examination the radiologist filled out a protocol (one protocol for each operator) that included different types of pathology that might be seen in an ultrasound examination of the kidneys such as the renal parenchyma, normal or thin, echogenicity, normal or increased, the presence or absence of hydronephrosis, presence or absence of renal masses, presence or absence of cysts, how many and the size of the cysts. The size of the kidneys was also measured. The protocols were compared for inter-reader and inter-operator agreement. 


\section{STATISTICAL METHODS}

In this thesis, different calculations were used, depending on the research question and the approach. In all four studies, predetermined protocols were used with different types of pathology that can be seen in an US examination of the kidneys, gallbladder and liver. Agreement between reviewers and operators was measured.

In paper I, the findings from the two methods were compared using protocols with different types of pathology. Agreement between the two methods was assessed by calculating the kappa coefficient and supplementing this with the agreement in percent (53). kappa $=1$ implies perfect agreement and kappa $=0$ suggests that agreement is no better than what could be obtained by random chance. McNemar's test for matched data, with exact computation from the binomial distribution was used to determine whether there was a systematic difference resulting in a higher frequency of positive findings with either of the methods. The number and size of cysts, concrements and polyps were compared between the methods. The limit for significance was set at $p=0.05$.

In paper II, the examinations made by a radiographer were reviewed by three radiologists. At the review, the radiologists filled out a protocol. The protocols were compared for intra-observer and inter-observer agreement, with a four-week interval. The kappa coefficient was used to assess the agreement, and was supplemented with agreement expressed as a percent (54). The kappa or percent agreement was not calculated in cases with less than three observations in either category (53). Friedman's test was used to determine if there was a significant difference between the three radiologists' observations. In cases where Friedman's test indicated a significant difference, Conover's test was applied for pairwise comparisons between reviewers and review occasions. Calculations were made with BrightStat version 1.2.0 (55). For the question concerning, increased echogenicity in the liver, weighted kappa was used, considering the four different levels of increased echogenicity (53).

In paper III, the examinations were carried out by a sonographer, and the review was made by two different radiologists. The radiologists filled out a form, both before and after the intravenous contrast. The forms included various types of pathology. Agreement between observers was assessed as percent agreement and kappa statistics (56). Conditional logistic regression was used to compare the frequencies of reported findings between observers and between examinations before and after the intravenous contrast was administered (57). The number and size of focal findings in those patients 
where such findings were reported, were analyzed using a mixed-effects analysis of variance. All analyses were carried out in Stata 13.1 (Stata Corp, College Station, TX, USA).

In paper IV, each patient was examined by one sonographer and one radiologist within the same session. All examinations were reviewed by two different radiologists. Agreement between readers and operators was assessed as agreement with kappa statistics (56). Inter-operator and interreader agreement for measurements, expressed as intra-class correlation (ICC) which takes values from zero (no agreement) to 1 (perfect agreement). The ICC is the proportion of variability in the observations which is due to the differences between pairs. McNemar's test was used for analysis if there was a systematic difference between readers and operators. Calculations were made with Bright Stat version 1.2.0 (55).

Possible interpretations of Kappa values were labeled as follows: $<0.00$ poor agreement, 0.00-0.20 slight agreement, 0.21-0.40 fair agreement, 0.41-0.60 moderate agreement, 0.61-0.80 substantial agreement, and 0.81-1.00 almost perfect agreement (56).

\section{ETHICAL CONSIDERATIONS}

The studies were designed in accordance with and followed the principles of the World Medical Association Declaration of Helsinki Ethical Principles for Medical Research Involving Human Subjects. For studies I and II the local ethical committee waived the need for an ethics committee review in this type of retrospective study. Permission to conduct studies III and IV was granted by the regional Ethical Review Board in Linköping. All patients included in study IV received written information in the mail two weeks in advance of the study. The patients gave written informed consent to having two sonographic examinations made by two different examiners using the standardized examination method. They were informed that their participation was voluntary and they could withdraw at any time. All patients' personal information and examinations were handled in accordance with the Personal Data Act. 


\section{RESULTS}

\section{PAPER I}

Radiographer-acquired and radiologist-reviewed ultrasound examination - agreement with radiologist's bedside evaluation.

The most common findings in the kidneys were renal cysts (Table 1). For the findings there was no significant difference in frequency between the two methods. Pathology was seen on five more occasions after reviewing the standardized examination method, than after the traditional method and for the latter there were two pathological observations that were not seen with the standardized method. The agreement between the methods varied between $78 \%$ and $100 \%$, as seen in Table 2. The lowest agreement was found for increased echogenicity of the renal parenchyma.

Findings in the kidneys not described in the predetermined protocol were seen in six of the 27 patients. In two cases, the findings agreed between the methods, such as enlarged prostate gland and liver metastases. In three cases, there were findings that were seen only when reviewing the standardized method, such as a bladder tumor and a small concrement in the right kidney in one patient, and thinning of the parenchyma in the left and the right kidneys in another patient. In one case, an enlarged prostate gland was noticed only with the traditional method.

For measuring the length of the kidneys it was seen in 22 cases using the standardized method, the kidneys were $0.5-1.0 \mathrm{~cm}$ smaller than with the traditional method. In three cases, there was exact agreement. Two examinations showed a slightly greater kidney length $(0.5-1.0 \mathrm{~cm})$ with the standardized method.

The frequencies of pathological findings in the gallbladder are given in Table 3 on p. 73 of paper I. No significant differences in frequency between the traditional and standardized methods were found. For these findings, the agreement varied between $86 \%$ and $100 \%$ with the lowest values for the number of concrements. The kappa values varied between 0.64 and 1.00 . The lowest kappa value was for presence of cysts and the highest for presence of concrements, and the size of these is seen in Table 4 on p. 73 of paper I.

In one of the 37 gallbladder examinations, liver cysts were found with both methods. Two cases with findings seen only with the standardized method included one with sludge in the gallbladder and one with slight steatosis in 
the liver of the examined part. Two other patients were found to have slight steatosis in the examined part of the liver and a liver cyst, respectively, and these findings were obtained only with the traditional method.

Table 1. Frequency of pathological findings in the kidneys

\begin{tabular}{|c|c|c|c|c|c|c|}
\hline \multicolumn{3}{|c|}{ Right kidney } & \multicolumn{3}{|c|}{ Left kidney } & \\
\hline Finding & $\begin{array}{l}\text { Patients } \\
\text { with } \\
\text { positive } \\
\text { finding } \\
\text { with } \\
\text { traditional } \\
\text { method }\end{array}$ & $\begin{array}{l}\text { Patients with } \\
\text { positive } \\
\text { finding with } \\
\text { standardized } \\
\text { method }\end{array}$ & $\begin{array}{l}\text { Patients } \\
\text { examined }\end{array}$ & $\begin{array}{l}\text { Patients } \\
\text { with } \\
\text { positive } \\
\text { finding } \\
\text { with } \\
\text { traditional } \\
\text { method }\end{array}$ & $\begin{array}{l}\text { Patients with } \\
\text { positive } \\
\text { finding with } \\
\text { standardized } \\
\text { method }\end{array}$ & $\begin{array}{l}\text { Patients } \\
\text { examined }\end{array}$ \\
\hline $\begin{array}{l}\text { Decreased cortical } \\
\text { thickness }\end{array}$ & 5 & 6 & 27 & 3 & 1 & 27 \\
\hline Hydronephosis & 4 & 3 & 27 & 2 & 3 & 27 \\
\hline $\begin{array}{l}\text { Increased } \\
\text { echogenicity }\end{array}$ & 2 & 4 & 27 & 1 & 5 & 27 \\
\hline Tumor & 1 & 1 & 27 & 1 & 1 & 27 \\
\hline Cysts & 11 & 11 & 27 & 10 & 11 & 27 \\
\hline Cysts $>2 \mathrm{~cm}$ & 5 & 4 & 27 & 4 & 4 & 27 \\
\hline
\end{tabular}


Table 2. Agreement between traditional and standardized method and corresponding kappa values for findings in the kidneys.

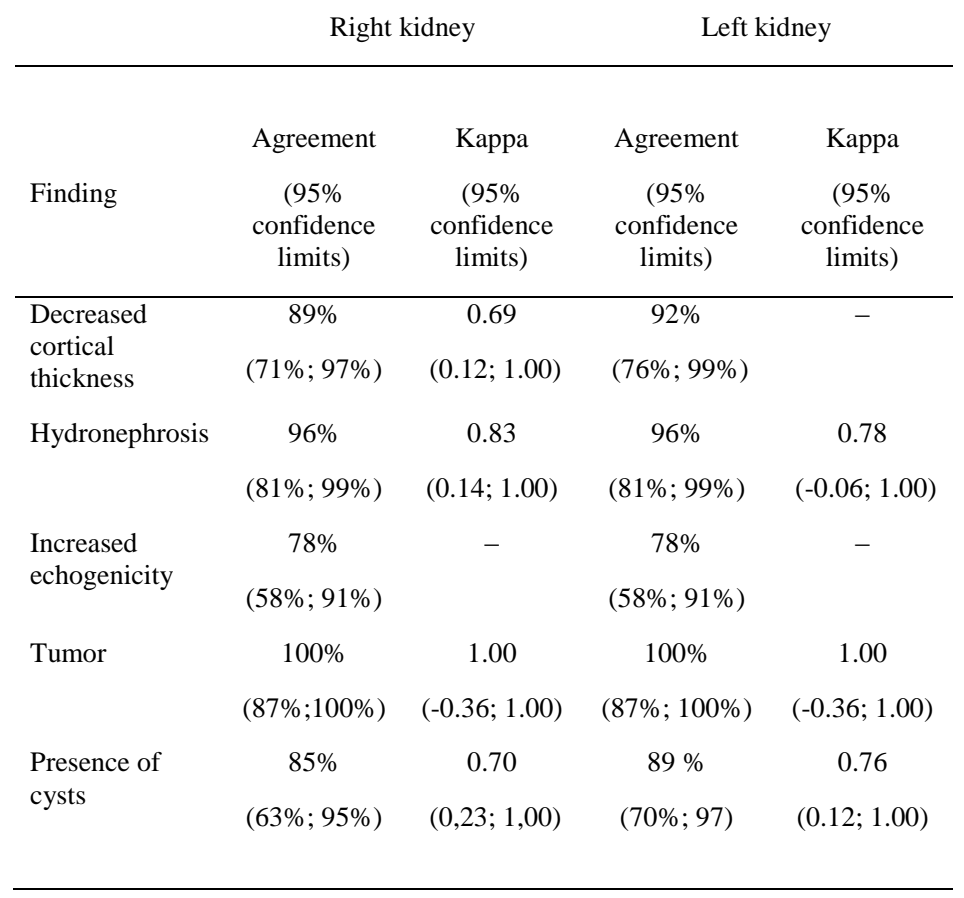




\section{PAPER II}

Do radiologists agree on findings in radiographer-acquired ultrasound liver examinations?

In this study, the most common finding was increased echogenicity in the liver, occurring in 38-42 of the 98 patients. Biliary obstruction was found only in 1-3 of the patients, depending on the observer and review occasion. The number of examinations with pathological findings is summarized in Table 1 on p. 515 of paper II.

Intra-observer agreement for the different types of liver pathology is summarized in Table 3. In general, the highest kappa values, with substantial or almost perfect agreement, were found for skip areas, with kappa values 0.73-0.90 and agreement in percent of 93-97\%, and for concrements in the gallbladder with kappa values 0.91-0.96 and agreement in percent of 97$99 \%$. Although the kappa value was occasionally slightly low, the agreement in percent was consistently quite high, from $70 \%$ upwards. For increased echogenicity in the liver and polyps in the gallbladder, the intra-observer agreement varied between moderate and almost perfect. Exceptions were seen for focal changes and need for further examination, where the agreement was fair to almost perfect.

The inter-observer agreement within each pair of observers (A and B, A and $\mathrm{C}, \mathrm{B}$ and $\mathrm{C}$ ) for different types of pathological findings in the liver is given in Table 4. A relatively high degree of inter-observer agreement was found for concrements in the gallbladder, which had almost perfect agreement, except for the need for further examination, where the radiologists had good intra-observer agreement, but varied in agreement between the different radiologists which was in most cases poor. For the other findings, the agreement was moderate to almost perfect, with somewhat lower values for focal changes. In the second reading there was no tendency towards higher agreement. 
Table 3. Intra-observer agreement between two readings four weeks apart, expressed as kappa value (percent agreement).

\begin{tabular}{lccc} 
& A1 vs. A2 & B1 vs. B2 & C1 vs. C2 \\
\hline Increased echogenicity & $0.85(91 \%)$ & $0.78(88 \%)$ & $0.51(70 \%)$ \\
Skip areas & $0.90(97 \%)$ & $0.81(93 \%)$ & $0.73(93 \%)$ \\
Focal changes & $0.76(94 \%)$ & $0.67(88 \%)$ & $0.89(97 \%)$ \\
$\begin{array}{l}\text { Concrements in gallbladder } \\
\text { Polyps in gallbladder }\end{array}$ & $0.91(97 \%)$ & $0.95(99 \%)$ & $0.96(99 \%)$ \\
$\begin{array}{l}\text { Need for further } \\
\text { examination }\end{array}$ & $0.86(97 \%)$ & $0.57(95 \%)$ & $0.65(92 \%)$ \\
\hline
\end{tabular}

Table 4. Inter-observer agreement, expressed as kappa value (percent agreement).

\begin{tabular}{lcccccc} 
& \multicolumn{3}{c}{ First reading } & \multicolumn{3}{c}{ Second reading } \\
\cline { 2 - 7 } & A vs. B & A vs. C & B vs. C & A vs. B & A vs. C & B vs. C \\
\hline $\begin{array}{l}\text { Increased } \\
\text { echogenicity }\end{array}$ & 0.74 & 0.51 & 0.60 & 0.66 & 0.53 & 0.55 \\
Skip areas & $(84 \%)$ & $(70 \%)$ & $(76 \%)$ & $(80 \%)$ & $(72 \%)$ & $(73 \%)$ \\
& 0.82 & 0.76 & 0.84 & 0.73 & 0.75 & 0.56 \\
Focal changes & $(94 \%)$ & $(93 \%)$ & $(95 \%)$ & $(89 \%)$ & $(93 \%)$ & $(84 \%)$ \\
& 0.50 & 0.70 & 0.60 & 0.37 & 0.85 & 0.40 \\
Concrements in & $(82 \%)$ & $(92 \%)$ & $(85 \%)$ & $(78 \%)$ & $(96 \%)$ & $(78 \%)$ \\
gallbladder & 1.0 & 1.0 & 1.0 & 0.84 & 0.84 & 0.93 \\
$\begin{array}{l}\text { Polyps in } \\
\text { gallbladder }\end{array}$ & $(100 \%)$ & $(100 \%)$ & $(100 \%)$ & $(95 \%)$ & $(95 \%)$ & $(98 \%)$ \\
& 0.58 & 0.93 & 0.69 & 0.69 & 0.48 & 0.48 \\
$\begin{array}{l}\text { Need for further } \\
\text { examination }\end{array}$ & $(94 \%)$ & $(99 \%)$ & $(95 \%)$ & $(95 \%)$ & $(88 \%)$ & $(89 \%)$ \\
& -0.05 & 0.29 & 0.04 & 0.1 & 0.46 & -0.12 \\
\hline
\end{tabular}




\section{PAPER III}

Visualization of liver lesions in standardized video-documented ultrasonography - inter-observer agreement and effect of contrast injection.

Out of the 115 patients, $112-113$ were considered to sufficient to make a medical diagnosis, as seen in Table I on p. 439 of paper III. The most common finding was cysts, with a frequency of $29-30 \%$ before and $31-32 \%$ after contrast injection. Metastases were seen in 5-6\% before and 9-10\% after contrast injection.

In 12 cases where at least one observer noted a metastasis in at least one of the examinations, the finding of metastasis was confirmed with CT. In 11 of the 12 cases, the CT examination took place within one month. Five of the patients were deceased before any CT examination took place, and no histopathological diagnoses could be found in the patients' medical records.

The difference in frequency between contrast-enhanced and non-enhanced US was significant for all focal lesions, for metastases, and for cysts, but not for "other focal findings" (Table I on p. 439 of Paper III). One other common finding was steatosis in the liver. The frequency of focal findings varied considerably between the eight segments, with the highest frequency in segment 6 and the lowest in segment 1, as seen in Table II on p. 440 of paper III. With one exception (segment 5), no significant systematic difference between observers was noted. A small but significant increase in the number of reported lesions was noted (Table 5). The size of the focal lesions did not differ between examinations before and after contrast injection, nor between the two radiologists' assessments.

In general, there was good agreement (90\%-97\%) between the observers before and after contrast injection (Table 6). Two exceptions were focal findings before contrast injection and the need for further examination after contrast injection, when the agreement was $86 \%-87 \%$. On the other hand, when the agreement was evaluated with the kappa coefficient, poor or moderate agreement was found for those questions (diagnostic examination, other focal findings, and need for further examination) where the frequency of positive answers was either below $10 \%$ or above $90 \%$. For the remaining questions (focal findings, metastases, and cysts), the kappa values were 0.70 or higher. 


\section{Table 5.}

Size and number of focal lesions without and with intravenous contrast. Effect of intravenous contrast evaluated with mixed-effects analysis of variance.

\begin{tabular}{lcccccc} 
& $\begin{array}{c}\text { Without intravenous } \\
\text { contrast }\end{array}$ & $\begin{array}{c}\text { With intravenous } \\
\text { contrast }\end{array}$ & Significance levels \\
\cline { 2 - 7 } & $\begin{array}{l}\text { Observer } \\
\mathrm{A}(n=43)\end{array}$ & $\begin{array}{l}\text { Observer } \\
\mathrm{B}(n=42)\end{array}$ & $\begin{array}{c}\text { Observer } \\
\mathrm{A}(n=47)\end{array}$ & $\begin{array}{c}\text { Observer } \\
\mathrm{B}(n=46)\end{array}$ & Contrast & Observer \\
\cline { 2 - 7 } $\begin{array}{l}\text { Number of lesions, } \\
\text { mean (SD) }\end{array}$ & $2.3(1.5)$ & $2.3(1.6)$ & $2.4(1.5)$ & $2.6(1.6)$ & $p=0.005$ & $p=0.266$ \\
$\begin{array}{l}\text { Lesion diameter, } \\
\text { mean (SD), mm }\end{array}$ & $19(15)$ & $19(13)$ & $18(15)$ & $18(13)$ & $p=0.641$ & $p=0.635$ \\
& & & & & & \\
\hline
\end{tabular}

\section{Table 6.}

Agreement between observers without and with intravenous contrast $(n=115)$. Effect of intravenous contrast on agreement in percent evaluated with conditional logistic regression.

\begin{tabular}{lccccc} 
& \multicolumn{2}{c}{ Without intravenous contrast } & With intravenous & contrast & \\
\cline { 2 - 4 } & $\begin{array}{c}\text { Agreement } \\
(\%)\end{array}$ & kappa & $\begin{array}{c}\text { Agreement } \\
(\%)\end{array}$ & kappa & $\begin{array}{c}\text { Significance } \\
\text { level }\end{array}$ \\
\hline $\begin{array}{l}\text { Diagnostic } \\
\text { examination }\end{array}$ & 96.5 & 0.316 & 97.4 & 0.387 & $p=0.644$ \\
Focal findings & 86.1 & 0.719 & 90.4 & 0.836 & $p=0.141$ \\
Metastasis & 97.4 & 0.756 & 94.8 & 0.699 & $p=0.311$ \\
Cyst & 90.4 & 0.768 & 92.2 & 0.819 & $p=0.410$ \\
$\begin{array}{l}\text { Other focal finding } \\
\text { Need for further }\end{array}$ & 92.2 & 0.141 & 96.5 & 0.483 & $p=0.141$ \\
examination & 92.2 & 0.267 & 87.0 & 0.235 & $p=0.115$ \\
\hline
\end{tabular}




\section{PAPER IV}

Do radiologists agree when reviewing ultrasound examinations performed by a sonographer and a radiologist?

Out of the 98 patients examined, all examinations were considered to be sufficient to make a diagnosis. The most common findings were cysts, which were seen in the right kidney in 32-36 cases and in the left kidney in 34-40 cases. The total number of cysts detected in the 98 patients varied from 118 to 137 between the reviewing radiologists, in the results. As for more severe condition such as tumors these were found in the right kidney in 8-10 cases and in the left kidney in 3-8 cases. Hydronephrosis, the least common finding, was seen on each side in 1-3 cases, seen in Table 1 p. 14 in paper IV.

The mean measurement results showed a small variation between operators, readers and left and right side, as seen in Table 7.

Mainly, the agreement in findings between operators was high, with kappa values above 0.78 , except for hydronephrosis of the right kidney. For this finding, only a few cases had a positive result, and the readers agreed in 96 to $98 \%$ of cases. The inter-reader agreement was slightly lower than the inter-operator agreement, although the confidence intervals overlapped extensively. The lowest kappa values, below 0.60 (still with an agreement in percent of 87-95\%), were seen for hydronephrosis, tumor and decreased cortical thickness Table 3 p. 17 in paper IV.

Significant systematic differences between the operators (readers) were found only for cysts, which were notably more frequent for operator 1 (reader 1).

For measuring the length of kidneys and the sizes of cysts, both the interoperator and the inter-reader agreement assessed as ICC were high, mostly above 0.80 (Table 8 ). 
Table 7. Measurement results for different operators and readers. Mean (SD)

\begin{tabular}{lcccc} 
& \multicolumn{2}{c}{$\begin{array}{c}\text { Operator 1 } \\
\text { (radiographer) }\end{array}$} & $\begin{array}{c}\text { Operator 2 } \\
\text { (radiologist) }\end{array}$ \\
\cline { 2 - 5 } Measure & Reader 1 & Reader 2 & Reader 1 & Reader 2 \\
\hline Length of right kidney, cm & $10.6(1.15)$ & $10.7(1.17)$ & $10.5(1.63)$ & $10.5(1.19)$ \\
Length of left kidney, cm & $10.8(1.08)$ & $10.8(1.60)$ & $10.8(1.68)$ & $10.8(1.66)$ \\
$\begin{array}{l}\text { Size of largest cyst, right kidney, } \\
\mathrm{cm}\end{array}$ & $1.04(1.60)$ & $0.9(1.65)$ & $1.06(1.60)$ & $0.9(1.49)$ \\
Size of largest cyst, left kidney, cm & $1.12(1.59)$ & $1.03(1.65)$ & $1.11(1.79)$ & $1.03(1.65)$
\end{tabular}

Table 8. Inter-operator and inter-reader agreement for measurements, expressed as intra-class correlation (ICC).

\begin{tabular}{|c|c|c|c|c|}
\hline \multirow[b]{3}{*}{ Measure } & \multirow{2}{*}{\multicolumn{2}{|c|}{$\begin{array}{l}\text { Inter-operator agreement } \\
\text { ICC (95\% confidence limits) }\end{array}$}} & \multirow{2}{*}{\multicolumn{2}{|c|}{$\begin{array}{c}\text { Inter-reader agreement } \\
\text { ICC (95\% confidence limits) }\end{array}$}} \\
\hline & & & & \\
\hline & Reader 1 & Reader 2 & $\begin{array}{c}\text { Operator 1 } \\
\text { (radiographer) }\end{array}$ & $\begin{array}{c}\text { Operator 2 } \\
\text { (radiologist) }\end{array}$ \\
\hline Length of right kidney, $\mathrm{cm}$ & $\begin{array}{c}0.86 \\
(0.80-0.90)\end{array}$ & $\begin{array}{c}0.89 \\
(0.83-0.93)\end{array}$ & $\begin{array}{c}0.90 \\
(0.85-0.93)\end{array}$ & $\begin{array}{c}0.91 \\
(0.86-0.94)\end{array}$ \\
\hline Length of left kidney, $\mathrm{cm}$ & $\begin{array}{c}0.78 \\
(0.69-0.85)\end{array}$ & $\begin{array}{c}0.94 \\
(0.91-0.96)\end{array}$ & $\begin{array}{c}0.81 \\
(0.72-0.87)\end{array}$ & $\begin{array}{c}0.95 \\
(0.93-0.97)\end{array}$ \\
\hline $\begin{array}{l}\text { Size of largest cyst, right } \\
\text { kidney, cm }\end{array}$ & $\begin{array}{c}0.96 \\
(0.94-0.97)\end{array}$ & $\begin{array}{c}0.94 \\
(0.92-0.96)\end{array}$ & $\begin{array}{c}0.80 \\
(0.71-0.86)\end{array}$ & $\begin{array}{c}0.84 \\
(0.87-0.90)\end{array}$ \\
\hline $\begin{array}{l}\text { Size of largest cyst, left } \\
\text { kidney, cm }\end{array}$ & $\begin{array}{c}0.82 \\
(0.74-0.87)\end{array}$ & $\begin{array}{c}0.89 \\
(0.83-0.92)\end{array}$ & $\begin{array}{c}0.90 \\
(0.84-0.92)\end{array}$ & $\begin{array}{c}0.75 \\
(0.65-0.82)\end{array}$ \\
\hline
\end{tabular}

All intra-class correlations significant at $P<0.001$ level 


\section{DISCUSSION}

The focus of this thesis was to evaluate a standardized US method that could be useful in clinical practice, with an opportunity to review an entire ultrasound examination stored as cine-loops at a workstation. The results of the four quantitative studies showed good agreement between and within observers when reviewing standardized ultrasound examinations. There was also good agreement between different examiners even though they had different levels of experience and education.

Currently, the most common practice when documenting US examinations is to store still images. This method offers no or limited possibilities for a re-evaluation of an US examination. If a new clinical question should arise after the examination, re-evaluation is often not useful $(44,45)$. A study by Faschingbauer et al. compared the diagnostic performance in a group of examiners with four different levels of experience of gynecological US. Their results showed an importance of an increasing level of experience when interpreting static images (48). This can be interpreted that experience and a high level of education are important factors in US, when the stored examination only consists of static images.

The study by Strauss et al. considered that the value of reviewing static US images is very limited, and the echogenicity of the liver is affected by the ultrasound machine settings. Their study also showed that radiologists may differ considerably in their assessment of steatosis when reviewing static images. The intra-observer agreement for the three different examiners varied between kappa 0.51 and 0.63 and the agreement in percent was between $54.7 \%-63.7 \%$. The difference from our study II was that they retrospectively reviewed static images. This could certainly have influenced the inter-observer agreement in their study, which showed lower kappa values and agreement in percent compared to our study.

US cannot be used to precisely measure fat in the liver, or to detect small changes in steatosis (58). Some studies performed with US, assessing the echogenicity of liver parenchyma, have been based on subjective impressions $(2,58)$. With that in mind, it is clear that there is a need for a method that is comparable with an examination in real time. Cine-loops are claimed to be comparable with real time. It has been shown that there is a better certainty in excluding pathology in real time examinations compared to reviewing static US images, when analyzing static images, the dynamic aspect is lost and some pathology can be misinterpreted (44). 
If the US examination is carried out in the traditional manner, training in pathology, anatomy, ultrasound physics, and experience are all necessary factors for the examiner, and the report should be written immediately after the examination, as only static images are stored in the PACS (46). It is only the examiner who knows what has been observed before and after the static images.

A previous study by Jandinski et al. showed an increased detection rate for small renal cysts when the examiners used cine-loop documentation with the opportunity to review the entire examination at a workstation (7). It has also been found in earlier studies that video- or cine-loop documentation can be used with positive results when US examinations are reviewed after the examination $(7,9-11,44,59)$.

Ultrasound is often considered to be observer- and operator-dependent (58). This emphasizes the need for a more stringent and less variable way of working with ultrasound. What we have suggested in this thesis is to work with US in a standardized manner in order to make it less operatordependent.

Most examinations conducted in radiology today, such as CT and MRI, have standardized methods where examinations are carried out according to strictly defined examination protocols, so that the influence of the operator is minimized (60).

In paper I, where the purpose was to compare the findings when using the new standardized method with a traditional method used at other hospitals in Sweden, the agreement between the two methods varied between $78 \%$ and $100 \%$. This demonstrates fairly good results when comparing findings between reviewers. On some occasions, there were a few more findings observed with the standardized method than with the traditional, such as a bladder tumor and a small concrement in the right kidney in one patient, and thinning of the parenchyma in the left and the right kidneys in another patient. After the examination with stored cine-loops, the radiologist had the possibility to review the examination one or several times. This can result in the radiologist detecting pathology that was not seen in the examination room when the patient was examined. One clinically important result is that the findings of serious pathology were not missed by any of the methods evaluated, exemplified by the presence of kidney tumors with an agreement of $100 \%$. Both methods showed that one of the 27 patients had a tumor in the right kidney and one patient had a tumor in the left kidney. None of the findings was found to occur significantly more often with one of the methods. However, the material in study I is limited, 
this has probably affected the outcome. It nevertheless shows that the tumor was noted.

The results of paper II showed a fairly good agreement between the three radiologists, who all had long US experience, but in one case only short experience of the standardized method. The intra-observer agreement was slightly higher than inter-observer agreement. This indicates that the radiologists were more consistent in using their own criteria based on their own experience. Observer $\mathrm{C}$, who had never worked with recorded examinations, underwent a two-week introduction to learn how to work with the standardized method and to review an examination made by someone else. This radiologist had almost equal results to the other two radiologists in this study regarding the intra-observer and inter-observer agreement. This can also be interpreted as demonstrating that reviewing cine-loops will give an overall assessment of US examinations.

In paper III, which used an intravenous contrast agent to examine patients with a diagnosed colorectal cancer, the radiologists observed focal findings in slightly more cases after the intravenous contrast compared to unenhanced US of the stored cine-loops. As for the inter-observer agreement, the radiologists were fairly consistent in their assessment. They both had a high level of experience and education.

It is often asserted that standardized and adequate training is needed to obtain optimal and reproducible results from US examinations, including CEUS (17). We have seen an important advantage when examining in a standardized way, as it is possible to compare the examination before and after contrast injection in identical views. In a study by Quaia et al. when a retrospective review of cine-loops of liver tumors with CEUS was made, where the reviewers had one to 10 years of experience of abdominal US, it was shown that the diagnostic performance when reviewing cine-loops of CEUS in liver tumor characterization was dependent on the observer's level of experience (61). This standardized technique, together with the use of an organ scheme might be a helpful tool for making even small findings when using CEUS.

Paper IV had a similar methodological structure as paper I where the examination was conducted by one radiographer/sonographer and one radiologist during the same session. The agreement was slightly better between the operators than the readers. The order of examinations by sonographer and radiologist alternated randomly, so that the reviewing radiologists would not know who performed the examination, which might otherwise have affected the result. However, one of the radiologists said that after a few examinations it was possible to identify the examiner. A strength 
of this study was that the readers did not work together and therefore could not influence each other's practical skills. Still, they had almost similar results when reviewing the examinations at a workstation. On the other hand, a possible limitation of the study could be that the radiologist and the sonographer had been working together and had used the same standardized method for some years and thus might have influenced each other's practical skills when examining patients.

With increasing demands for medical imaging and radiologists' time, radiographers' findings have been shown to provide accurate diagnostic results. Benefits have been claimed in terms of reduced patient waiting times, freeing up of radiologists for other duties, cost-effectiveness, and greater potential for recruitment and retention with higher levels of job satisfaction for radiographers (62-64). It has also been suggested that radiographers who find no abnormalities, or straightforward abnormalities, such as gallstones or renal cysts, will be able to issue their own reports (64). For this reason there might be a possibility for a radiographer to perform an US examination with a standardized method and cine-loops saved in the dedicated PACS. When using this technique it could create an opportunity for radiographers to get into an area that has so far been reserved for radiologists and sonographers.

A possible solution is to use the knowledge and experience of the radiographer when using the standardized method presented in this thesis, with standardized examination protocols, with the possibility to review the entire examination at a workstation afterwards. An advantage of working with standardized examinations is that it gives the opportunity to review the US films many times and compare a new and an old examination, and more easily identify a new finding.

The use of this technique might be efficient and secure when education of new radiologists, sonographers and radiographers is given since skills and progress can be monitored at a workstation after the examination. This consistent and systematic way of acquiring image data can potentially increase the accuracy of the method. This standardized technique could make US more comparable to other modalities used in radiology such as CT or MRI, where there are already standardized examination protocols. 


\section{METHODOLOGICAL CONSIDERATIONS}

In all four studies, the recruitment of patients led to a low proportion of pathological findings, which may not have been the case if there had been a selection of patients with a certain type of pathology or finding. This selection in the four studies explains the low kappa in combination with high agreement in percent. To get a satisfactory result in agreement one would have needed more patient with pathological findings $(53,54)$. The low proportion of pathological findings have certainly affected the results.

In study I, two different methods were compared when examinations were made by a radiologist using a traditional method and a radiographer using the standardized method. One obvious limitation of this study is the low number of patients with mostly no pathology making the confidence intervals wide and the results less accurate. We suspect that a larger amount of material might give more reliable results. It is also important to ascertain whether the results found here with one radiographer and two radiologists who had worked closely together for some years can be generalized.

In study II, all examinations were made by one radiographer using the standardized method. However, it should be noted that two of the three observers had worked closely together for at least 15 years in the same sonography unit and may thus have influenced each other's practical skills. For this reason they might have produced better agreement levels, this was seen in a few cases when increased echogenicity in the liver were assessed.

In addition, a consideration should be noted that even with 98 patients included in the study and the examinations were randomly rearranged it could still be possible for a radiologist to recognize the examination after 4 weeks if there were some specific pathology or anatomy present. A strength of the study could be that the third radiologist had been working at another hospital and was not used to evaluate dynamic US films at a workstation. Radiologist $\mathrm{C}$ was not influenced by the other two radiologists.

Likewise, in study III the reviewers had worked closely together for several years in the same hospital and may thus have influenced each other's practical skills. When generalizing to other circumstances, it is therefore not certain whether equally high inter-observer agreement can be expected. In several cases, the two radiologists did not agree on what specific segment of the liver the focal lesions belonged to. One of the radiologists remarked that it was difficult to identify lesions close to the boundary of the different segments. In addition, the reader's experience of ultrasound will influence the diagnostic assessment. It should be noted that observer A, who had 20 
years of experience, indicated a need for further examination after intravenous contrast in only five cases, whereas observer B, with eight years, did so in 16 cases. In this study it might have been suitable to included two reviewers with similar experience of, and time spent working with US examinations. A more serious limitation of study III was the lack of a reference method such as CT or MRI, for evaluating this standardized US method when using intravenous contrast.

In Study IV, each patient was examined by one sonographer and one radiologist during the same visit, the examination time was only a few minutes longer than it would have been with only one examiner. The order of the examination by the sonographer or radiologist was alternated randomly in order to prevent the reviewer from identifying who conducted the examinations. Nevertheless, one of the reviewing radiologists said that she was able to identify the examiner. We presume that this observation did not affect the results of the review. There is an expected possibility that radiologists and sonographers work differently due to their different educational backgrounds. A strength of this study was that the readers did not work at the hospital where the study was conducted. Therefore, we can conclude that they did not influence each other's practical skills. Still, they had almost the same results when reviewing the examinations at a workstation. However, as in previous studies the radiologist and the sonographer had been working together and had used the same standardized method for some years and thus might have influenced each other's practical skills when examining patients.

\section{STATISTICAL ANALYSES}

The data was analyzed with the kappa coefficient and was calculated to compare how different radiologists evaluated the same examinations in studies I, II and IV. Kappa is useful for showing how different evaluations agree and is suitable for studies where there is no reference standard such as in this case, CT or MRI. Besides the kappa coefficient in study II, weighted kappa was used for the ordinal data for increased echogenicity in the liver where there were four levels of echogenicity namely normal, slightly increased, moderately increased, or greatly increased. Kappa was complemented with agreement in percent in studies I, II and IV, which has been recommended by other research (65). High agreement in percent and low kappa values in studies I, II and IV. If the negative findings is large relative to the positive, the agreement in regard to negative findings will 
dominate and cause an imbalance in the results, which may give a false impression, $(53,66)$ This was seen in studies I, II and IV.

Conditional logistic regression was used in study III to compare the frequencies of reported findings, and the effect of intravenous contrast between observers and between examinations, before and after intravenous contrast. This statistical technique is suitable for relating paired data on a binary scale. The number and size of focal findings in those patients where they were reported were analyzed using mixed-effects analysis of variance since numerical values were compared.

In study III when assessing the length of kidneys and the sizes of cysts, ICC was used for measurements. Both the inter-operator and the inter-reader agreement assessed as ICC was high.

A more selective choice of patients, instead of the consecutive material used, is assumed to have resulted in a better balance between negative and positive outcomes.

\section{GENERALIZABILITY}

This thesis includes four quantitative studies which in total examined almost 380 outpatients with the use of the standardized US method, with one exception, since study I also included a traditional method that is normally used at other hospitals in most European countries. The generalizability is limited by the fact that the examinations were conducted by one radiographer/sonographer and two different radiologists. It would have been desirable to have more examiners in all four studies with different levels of education.

On the other hand, for the review, there have been six different radiologists, three of them worked at the same hospital and two worked at two different hospitals, and one of the radiologists had previously worked in a different country. The reviewing radiologists had various lengths of experience in ultrasound and they still had good results as regards agreement when they reviewed the examinations in the four studies, this was interpreted as a positive effect on the generalizability. 


\section{TOPICS FOR FUTURE RESEARCH}

This thesis has generated several new research questions. In the future, it would be relevant to compare this standardized US method with another modality within radiology, such as CT and MRI. Using CT or MRI as the reference method, one could then determine the sensitivity and specificity of this standardized US method.

It would be interesting to evaluate levels of agreement between examiners who have been trained in different environments such as a team of sonographers, radiographers and radiologists with different levels of experience, not working in the same hospital, when using the standardized method.

A study similar to study I, comparing standardized and traditional US diagnosis, could be performed with a larger body of material and a more targeted selection with a specific pathology. Since we have not investigated the relative importance of cine-loop documentation vs. a standardized protocol, another potential study could be to investigate how the assessment of static images agrees between and within observers. It would also be interesting to examine the use of a standardized reporting system.

It would be of great clinical value to assess the diagnostic accuracy of the standardized ultrasound examination technique when used with intravenous contrast agent, by correlating it with a reference standard.

A larger number of patients, in particular patients with pathological findings, would increase the validity of any additional study. 


\section{CLINICAL APPLICATION}

Today, in the radiology departments in Sweden the radiographer conducts the examinations using CT, MRI and conventional radiography. The results of studies I and IV suggest that the examiner is replaceable, whereas the reviewer is not. This could be interpreted that radiographers are able to perform US examinations in a standardized manner in a new area, an area that so far has been exclusively for radiologists. Advantages include freeing up time for the radiologists since the radiographer can make a large number of examinations with a clear clinical question.

In a situation with limited healthcare resources, this is likely to result in lower costs or more efficient use of available resources, provided that the image quality can be kept at an appropriate level. This may among other things, result in a development of the radiographers' professional role. In our clinical practice we have observed that a radiologist can evaluate around 10 examinations per hour that previously have been performed by a radiographer (4), whereas when radiologists perform the examination it typically takes 20-30 minutes, including both preparation and writing the report. If the radiographer conducts the examination, this may result in radiologists having more time for acute and more complex medical questions an important result also noted by previous studies in the literature (62).

With appropriately trained radiographers working in close collaboration with radiologists, it is possible for radiographers to perform standard diagnostic US examinations with a standardized method if the entire examination can be reviewed at a workstation. It has been shown that sonographers and radiographers are able to differentiate negative from positive findings in routine abdominal US with an accuracy comparable to experienced radiologists (64).

An advantage of working with standardized examination protocols is that it will give the opportunity to review the US films and compare new and old examinations at a workstation. It can also provide the radiologist the opportunity to observe findings that were not noted at the time of examination if new clinical questions are brought up at a later time.

Documentation of cine-loops stored in PACS and the ability to review the examinations it will be possible to provide the radiologist with a more complete information of the examination, even if it has been performed by someone else. The standardized technique is also a favorable method for the 
education of new radiologists in US, since once can review the entire examination at a workstation and discuss findings without having a patient present. There is also a possibility of getting a second opinion from a more experienced radiologist, which helps in maintaining a high level of expertise in ultrasound examinations.

When examining the kidneys with the standardized technique the aim is to involve the entire kidney in one cine-loop, and the transducer is angled relative to the ribs and bowel. This means that the examiner, in some cases, cannot angle the transducer in the exact longitudinal axis. Comparison of findings from the protocols showed that in the traditional method, when the kidneys was measured by the reviewer it appeared that the kidneys measured from 0.5 to $1.0 \mathrm{~cm}$ longer in 22 cases of 27 . Measurement of the kidneys in a cine-loop with the standardized method does not seem to give an optimal result, which may be due to how the examiner has held the transducer towards the patient's body. This demonstrates that measurement of the kidneys in younger children and adults with the standard method should always include a single image of the kidneys in the longitudinal axis.

The introduction of US contrast media has increased the accuracy and applications in areas such as liver lesion detection and characterization, for differentiating benign from malignant lesions of the liver. The availability and lack of ionizing radiation can make CEUS with a standardized technique a very interesting option for treatment follow-up in patients who have undergone surgery for colorectal cancer. CEUS is also useful for answering many clinical questions concerning the kidneys, including detection and characterization of lesions. 


\section{CONCLUSIONS}

- There was satisfactory agreement between the new standardized method and the traditional method for examining the gallbladder and the kidneys. This indicates that ultrasound examinations performed by a radiographer and analyzed off-line by a radiologist can be a useful alternative to bedside examinations by a radiologist.

- An adequately good inter-observer agreement between radiologists was seen when reviewing ultrasound examinations of the liver and biliary system acquired by a trained radiographer. In general, intraobserver agreement was higher than inter-observer agreement. This indicates that the radiologists were more consistent intra-observer than inter-observer.

- We found good agreement between two radiologists reviewing images of CEUS liver examinations, acquired by a sonographer using a standardized ultrasound technique, after surgery for colorectal cancer. The injection of contrast medium increased the visibility of liver lesions.

- There was a notably better inter-operator agreement than inter-reader when using the standardized cine-loop technique. This might indicate that the operator is more exchangeable than the reader. 


\section{SVENSK SAMMANFATTNING}

Ultraljud har blivit en vanlig metod vid undersökning av buken. Detta kan tänkas bero på den tekniska utvecklingen av ultraljudsutrustningar när det gäller bildkvalitet, men även på att ultraljud är förhållandevis säkert, billigt, snabbt att utföra och utan joniserande strålning. Många remittenter väljer ultraljud som förstahandsval för sina patienter, och detta leder till hög efterfrågan, med risk för långa väntetider för patienterna. Det finns även ett krav på kvalitet som gör det angeläget att söka efter nya rutiner som kombinerar den diagnostiska noggrannheten hos radiologutförda ultraljudsundersökningar med de ekonomiska fördelarna av att en sonograf eller röntgensjuksköterska utför undersökningarna. En möjlighet är att använda strikt standardiserade undersökningsprotokoll och dokumentation av cine-loopar som ger radiologen eller den som undersöker tillgång till all relevant information efter undersökningen.

Den dynamiska dokumentationen sker både longitudinellt och transversellt genom det organ eller område som är av intresse. Cine-loopar är dynamiska filmer som täcker 5-10 cm på 5-10 sekunder. Undersökningen utförs enligt ett schema med ca 10 svep beroende av vilket organ som ska undersökas. Det medför att alla patienter undersöks på liknande sätt. Därefter sparas de dynamiska filmerna i det digitala bildarkivet, PACS (Picture archiving and communication system). Från PACS kan filmerna efter- och dubbelgranskas.

I dag används vid flera sjukhus i Sverige en ultraljudsmetod där statiska bilder sparas i PACS. En systematisk genomgång av det område eller organ som är av intresse utförs, men värdet av att eftergranska eller dubbelgranska statiska ultraljudsbilder är mycket begränsad.

Avhandlingens övergripande syfte var att utvärdera en standardiserade ultraljudsmetod som används vid Linköpings universitetssjukhus. Metoden började användas i kliniskt bruk 2002.

I de fyra delstudierna eftergranskades standardiserade ultraljudsundersökningar av radiologer. I studie I och IV undersöktes patienterna av både en röntgensjuksköterska och en radiolog vid samma tillfälle. I studie I inkluderades 64 patienter, och i studie IV 98 patienter som hade kallats till en ultraljudsundersökning. Alla undersökningar granskades i efterhand. I studie I användes en traditionell undersökningsmetod, där statiska bilder lagrades i PACS av radiologen, och en standardiserad ultraljudsmetod av röntgensjuksköterskan. I studie IV undersöktes patienterna endast med den standardiserade metoden. 
I studie II ingick 98 patienter, och i studie III 115 patienter. Dessa patienter undersöktes av en röntgensjuksköterska man använde endast den standardiserade metoden, och alla undersökningar i studie II och III eftergranskades av 2 - 3 radiologer. I studie III användes även ett intravenöst kontrastmedel och undersökningarna eftergranskades både före och efter intravenös kontrast.

Resultatet i den första delstudien, där vi jämförde en traditionell och den standardiserade ultraljudsmetoden, och alla undersökningar eftergranskades av två radiologer, visade att det inte fanns några systematiska skillnader mellan de två metoderna och att överensstämmelsen var god.

I den andra delstudien gjorde en röntgensjuksköterska undersökningarna med den standardiserade metoden och eftergranskningen utfördes av 3 erfarna radiologer vid två olika tillfällen. Resultatet visade en god överensstämmelse mellan de olika radiologerna och även mellan samma radiolog vid ett senare tillfälle. Det fanns inga systematiska skillnader mellan de olika radiologernas bedömningar.

I den tredje delstudien, där undersökningarna utfördes före och efter intravenös kontrast av en sonograf, visade resultatet god överensstämmelse mellan de 2 olika radiologerna som eftergranskade undersökningarna av patienter som genomgått operation för kolorektal cancer med frågeställning metastaser.

I den fjärde delstudien, där vi jämförde två olika undersökare med olika utbildningsnivåer och två olika eftergranskare, fann vi att med en standardiserad ultraljudsmetod och dokumentation av cine-loopar var överensstämmelsen något bättre mellan undersökarna än mellan eftergranskarna.

Sammanfattningsvis visade avhandlingens resultat att den standardiserade ultraljudsmetoden med lagrade cine-loopar, som utförs av en röntgensjuksköterska eller sonograf och analyseras i efterhand av en radiolog, är en lovande teknik. Resultaten i studie I och IV antyder att undersökaren kan vara utbytbar, men inte eftergranskaren. 


\section{ACKNOWLEDGEMENTS}

This study was carried out at the Radiology Department at the University hospital, Linköping, which is gratefully acknowledged. I want to express my warmest and sincere gratitude to everyone who supported me and in different ways contributed to this thesis.

I would especially like to thank:

My main supervisor, Professor Örjan Smedby for many interesting discussions, being supporting and inspiring during all phases and helping me with the statistical process in a very educational way. You have shown a great patience. I have learned so much.

My co-supervisors, Staffan Wirell for interesting discussions, encouragement and giving me motivation, Marcus Ressner for all positive support and encouragement during this time.

Co-authors, Doctors: Lars Thorelius, Anders Knutsson, Joachim Davidsson, Shazia Jamil, Ann-Lis Enlund and Kjell Jansson for reviewing all the examinations, you did it, and you did a great job!

Co-author, Doctor Robert Glavas for all support and encouragement.

Mathias Axelsson for the support, from the Radiology department at the University hospital in Linköping.

Birgitta Hagman and Susanne Hellberg for your encouragement and positive support, when I needed it.

Agneta Lindquist thank you for all support in the beginning of this journey, and that you believed in me.

My friend Ann-Sofie Zahlin, for always being there supporting me in all situations. My friends Kristina Breidner and Anita Öfverstedt you have always been supportive and encouraging.

Andreas and Mattias Tapper my wonderful sons always patience and supportive.

My sister Liselott Stenman for many interesting discussions. You have given me other perspectives on life.

My beloved Anders Holmgren, for always being there for me, you always supported me in all situations and believed in me.

All my colleagues, friends and family, Thank you! 


\section{REFERENCES}

1. Choi SH, Kim EK, Kwak JY, Kim MJ, Son EJ. Interobserver and intraobserver variations in ultrasound assessment of thyroid nodules. Thyroid. 2010;20(2):167-72.

2. Strauss S, Gavish E, Gottlieb P, Katsnelson L. Interobserver and intraobserver variability in the sonographic assessment of fatty liver. AJR Am J Roentgenol. 2007;189(6):W320-3.

3. Zwiebel WJ. Sonographic diagnosis of diffuse liver disease. Semin Ultrasound CT MR. 1995;16(1):8-15.

4. Thorelius L. Ultrasound in radiology--is there a future? Ultraschall Med. 2007;28(3):326-7.

5. Thorelius L. Sonodynamics fundamentals 2014 [cited 201427 February]. Available from: www.sonodynamics.com.

6. Stenman C, Thorelius L, Knutsson A, Smedby O. Radiographeracquired and radiologist-reviewed ultrasound examination--agreement with radiologist's bedside evaluation. Acta Radiol. 2011;52(1):70-4.

7. Jandzinski D, van Wijngaarden E, Dogra V, Fisher SG, Conde A, Rubens D. Renal sonography with 2-dimensional versus cine organ imaging: preliminary results. Journal of ultrasound in medicine : official journal of the American Institute of Ultrasound in Medicine. 2007;26(5):635-44.

8. Scott TE, Jones J, Rosenberg H, Thomson A, Ghandehari H, Rosta N, et al. Increasing the detection rate of congenital heart disease during routine obstetric screening using cine loop sweeps. Journal of ultrasound in medicine : official journal of the American Institute of Ultrasound in Medicine. 2013;32(6):973-9.

9. Dormagen JB, Gaarder M, Drolsum A. Standardized cine-loop documentation in abdominal ultrasound facilitates offline image interpretation. Acta Radiol. 2013. 
10. Bude RO, Fatchett JP, Lechtanski TA. The use of additionally trained sonographers as ultrasound practitioners: our first-year experience. Journal of ultrasound in medicine : official journal of the American Institute of Ultrasound in Medicine. 2006;25(3):321-7; quiz 8-30.

11. Gaarder M, Seierstad T, Soreng R, Drolsum A, Begum K, Dormagen JB. Standardized cine-loop documentation in renal ultrasound facilitates skill-mix between radiographer and radiologist. Acta Radiol. 2014.

12. Dietrich CFS, C.; Jedrzejczyk M. Ultrasound of the liver. CF D, editor. Bad Margentheim2010. 90 p.

13. Robbin ML, Lockhart ME, Weber TM, Tessler FN, Clements MW, Hester FA, et al. Ultrasound quality and efficiency: how to make your practice flourish. Journal of ultrasound in medicine : official journal of the American Institute of Ultrasound in Medicine. 2011;30(6):739-43.

14. Aspelin P, Pettersson H. Radiologi: Lund : Studentlitteratur, 2008

1. uppl.; 2008.

15. Danila M, Popescu A, Sirli R, Sporea I, Martie A, Sendroiu M. Contrast enhanced ultrasound (CEUS) in the evaluation of liver metastases. Med Ultrason. 2010;12(3):233-7.

16. Claudon M, Dietrich CF, Choi BI, Cosgrove DO, Kudo M, Nolsoe CP, et al. Guidelines and good clinical practice recommendations for Contrast Enhanced Ultrasound (CEUS) in the liver - update 2012: A WFUMB-EFSUMB initiative in cooperation with representatives of AFSUMB, AIUM, ASUM, FLAUS and ICUS. Ultrasound Med Biol. 2013;39(2):187-210.

17. Jang JY, Kim MY, Jeong SW, Kim TY, Kim SU, Lee SH, et al. Current consensus and guidelines of contrast enhanced ultrasound for the characterization of focal liver lesions. Clinical and molecular hepatology. 2013;19(1):1-16.

18. Nicolau C, Ripolles T. Contrast-enhanced ultrasound in abdominal imaging. Abdominal imaging. 2012;37(1):1-19. 
19. Ding H, Wang WP, Huang BJ, Wei RX, He NA, Qi Q, et al. Imaging of focal liver lesions: low-mechanical-index real-time ultrasonography with SonoVue. Journal of ultrasound in medicine : official journal of the American Institute of Ultrasound in Medicine. 2005;24(3):285-97.

20. Heiken JP. Distinguishing benign from malignant liver tumours. Cancer Imaging. 2007;7 Spec No A:S1-14.

21. Cokkinos DD, Antypa EG, Skilakaki M, Kriketou D, Tavernaraki E, Piperopoulos PN. Contrast enhanced ultrasound of the kidneys: what is it capable of? Biomed Res Int. 2013;2013:595873.

22. Piscaglia F, Bolondi L, Italian Society for Ultrasound in M, Biology Study Group on Ultrasound Contrast A. The safety of Sonovue in abdominal applications: retrospective analysis of 23188 investigations. Ultrasound Med Biol. 2006;32(9):1369-75.

23. Hangiandreou NJ. AAPM/RSNA physics tutorial for residents. Topics in US: B-mode US: basic concepts and new technology. Radiographics. 2003;23(4):1019-33.

24. Abu-Zidan FM, Hefny AF, Corr P. Clinical ultrasound physics. J Emerg Trauma Shock. 2011;4(4):501-3.

25. Evans DH, Jensen JA, Nielsen MB. Ultrasonic colour Doppler imaging. Interface Focus. 2011;1(4):490-502.

26. Thorelius L. Contrast-enhanced ultrasound for extrahepatic lesions: preliminary experience. Eur J Radiol. 2004;51 Suppl:S31-8.

27. ten Cate FJ. Ceus. Swiss Med Wkly. 2015;145:w14069.

28. Kaspar M, Partovi S, Aschwanden M, Imfeld S, Baldi T, Uthoff $\mathrm{H}$, et al. Assessment of microcirculation by contrast-enhanced ultrasound: a new approach in vascular medicine. Swiss Med Wkly. 2015;145:w14047.

29. Schneider A, Johnson L, Goodwin M, Schelleman A, Bellomo R. Bench-to-bedside review: contrast enhanced ultrasonography--a promising technique to assess renal perfusion in the ICU. Crit Care. 2011;15(3):157. 
30. Raisinghani A, Rafter P, Phillips P, Vannan MA, DeMaria AN. Microbubble contrast agents for echocardiography: rationale, composition, ultrasound interactions, and safety. Cardiol Clin. 2004;22(2):171-80, v.

31. Furuse J, Nagase M, Ishii H, Yoshino M. Contrast enhancement patterns of hepatic tumours during the vascular phase using coded harmonic imaging and Levovist to differentiate hepatocellular carcinoma from other focal lesions. Br J Radiol. 2003;76(906):385-92.

32. von Herbay A, Vogt C, Willers R, Haussinger D. Real-time imaging with the sonographic contrast agent SonoVue: differentiation between benign and malignant hepatic lesions. Journal of ultrasound in medicine : official journal of the American Institute of Ultrasound in Medicine. 2004;23(12):1557-68.

33. Xu LH, Cai SJ, Cai GX, Peng WJ. Imaging diagnosis of colorectal liver metastases. World J Gastroenterol. 2011;17(42):4654-9.

34. Mulvagh SL, Rakowski H, Vannan MA, Abdelmoneim SS, Becher H, Bierig SM, et al. American Society of Echocardiography Consensus Statement on the Clinical Applications of Ultrasonic Contrast Agents in Echocardiography. J Am Soc Echocardiogr. 2008;21(11):1179201; quiz 281.

35. Sirli R, Sporea I, Martie A, Popescu A, Danila M. Contrast enhanced ultrasound in focal liver lesions--a cost efficiency study. Med Ultrason. 2010;12(4):280-5.

36. Seitz K, Bernatik T, Strobel D, Blank W, Friedrich-Rust M, Strunk $\mathrm{H}$, et al. Contrast-enhanced ultrasound (CEUS) for the characterization of focal liver lesions in clinical practice (DEGUM Multicenter Trial): CEUS vs. MRI--a prospective comparison in 269 patients. Ultraschall Med. 2010;31(5):492-9.

37. Liguori C, Frauenfelder G, Massaroni C, Saccomandi P, Giurazza F, Pitocco F, et al. Emerging clinical applications of computed tomography. Med Devices (Auckl). 2015;8:265-78.

38. Kalender WA, Vock P, Polacin A, Soucek M. [Spiral-CT: a new technique for volumetric scans. I. Basic principles and methodology]. Rontgenpraxis. 1990;43(9):323-30. 
39.

Verdun FR, Racine D, Ott JG, Tapiovaara MJ, Toroi P, Bochud FO, et al. Image quality in CT: From physical measurements to model observers. Phys Med. 2015.

40. Sarracanie M, LaPierre CD, Salameh N, Waddington DE, Witzel T, Rosen MS. Low-Cost High-Performance MRI. Sci Rep. 2015;5:15177.

41. Tchelepi H, Ralls PW, Radin R, Grant E. Sonography of diffuse liver disease. Journal of ultrasound in medicine : official journal of the American Institute of Ultrasound in Medicine. 2002;21(9):1023-32; quiz 334.

42. Zanoli L, Romano G, Romano M, Rastelli S, Rapisarda F, Granata A, et al. Renal function and ultrasound imaging in elderly subjects. TheScientificWorldJournal. 2014;2014:830649.

43. Pallan M, Linnane J, Ramaiah S. Evaluation of an independent, radiographer-led community diagnostic ultrasound service provided to general practitioners. J Public Health (Oxf). 2005;27(2):176-81.

44. Van Holsbeke C, Yazbek J, Holland TK, Daemen A, De Moor $\mathrm{B}$, Testa AC, et al. Real-time ultrasound vs. evaluation of static images in the preoperative assessment of adnexal masses. Ultrasound Obstet Gynecol. 2008;32(6):828-31.

45. Rosen MP, Levine D, Carpenter JM, Frost L, Hulka CA, Western DL, et al. Diagnostic accuracy with US: remote radiologists' versus on-site radiologists' interpretations. Radiology. 1999;210(3):733-6.

46. Tegnander E, Eik-Nes SH. The examiner's ultrasound experience has a significant impact on the detection rate of congenital heart defects at the second-trimester fetal examination. Ultrasound Obstet Gynecol. 2006;28(1):8-14.

47. Yazbek J, Ameye L, Testa AC, Valentin L, Timmerman D, Holland TK, et al. Confidence of expert ultrasound operators in making a diagnosis of adnexal tumor: effect on diagnostic accuracy and interobserver agreement. Ultrasound Obstet Gynecol. 2010;35(1):89-93. 
48. Faschingbauer F, Benz M, Haberle L, Goecke TW, Beckmann MW, Renner S, et al. Subjective assessment of ovarian masses using pattern recognition: the impact of experience on diagnostic performance and interobserver variability. Archives of gynecology and obstetrics. 2012;285(6):1663-9.

49. Sinan $\mathrm{T}$, Leven $\mathrm{H}$, Sheikh M. Is fasting a necessary preparation for abdominal ultrasound? BMC Med Imaging. 2003;3(1):1.

50. Germain T, Favelier S, Cercueil JP, Denys A, Krause D, Guiu B. Liver segmentation: practical tips. Diagn Interv Imaging. 2014;95(11):100316.

51. Couinaud C, Delmas A, Patel J. Le foie : Études anatomiques et chirurgicales. Paris: Masson; 1957.

52. Marchal G, Tshibwabwa-Tumba E, Verbeken E, Van Roost W, Van Steenbergen W, Baert A, et al. "Skip areas" in hepatic steatosis: a sonographic-angiographic study. Gastrointest Radiol. 1986;11(2):151-7.

53. Feinstein AR. High agreement but low kappa: II. Resolving the paradoxes. J Clin Epidemiol. 1990;43:551-8.

54. Viera AJ, Garrett JM. Understanding interobserver agreement: the kappa statistic. Fam Med. 2005;37(5):360-3.

55. Stricker D. BrightStat.com: free statistics online. Comput Methods Programs Biomed. 2008;92(1):135-43.

56. Landis JR, Koch GG. The measurement of observer agreement for categorical data. Biometrics. 1977;33(1):159-74.

57. Breslow NE DN. Statistical Methods in Cancer Research The Analysis of Case-control Studies. 1. Lyon1980.

58. Mehta SR, Thomas EL, Bell JD, Johnston DG, Taylor-Robinson SD. Non-invasive means of measuring hepatic fat content. World J Gastroenterol. 2008;14(22):3476-83. 
59. Stenman C, Jamil S, Thorelius L, Knutsson A, Smedby O. Do radiologists agree on findings in radiographer-acquired sonographic examinations? Journal of ultrasound in medicine : official journal of the American Institute of Ultrasound in Medicine. 2013;32(3):513-8.

60. Jensch S, van Gelder RE, Florie J, Thomassen-de Graaf MA, Lobe JV, Bossuyt PM, et al. Performance of radiographers in the evaluation of CT colonographic images. AJR Am J Roentgenol. 2007;188(3):W249-55.

61. Quaia E, Alaimo V, Baratella E, Pizzolato R, Cester G, Medeot A, et al. Effect of observer experience in the differentiation between benign and malignant liver tumors after ultrasound contrast agent injection. Journal of ultrasound in medicine : official journal of the American Institute of Ultrasound in Medicine. 2010;29(1):25-36.

62. Smith TN, Baird M. Radiographers' role in radiological reporting: a model to support future demand. Med J Aust. 2007;186(12):62931.

63. Field LJ, Snaith BA. Developing radiographer roles in the context of advanced and consultant practice. J Med Radiat Sci. 2013;60(1):11-5.

64. Leslie A, Lockyer H, Virjee JP. Who should be performing routine abdominal ultrasound? A prospective double-blind study comparing the accuracy of radiologist and radiographer. Clin Radiol. 2000;55(8):6069.

65. Cicchetti DV, Feinstein AR. High agreement but low kappa: II. Resolving the paradoxes. J Clin Epidemiol. 1990;43(6):551-8.

66. Kundel HL, Polansky M. Measurement of observer agreement. Radiology. 2003;228(2):303-8. 


\section{Papers}

The articles associated with this thesis have been removed for copyright reasons. For more details about these see:

http://urn.kb.se/resolve?urn=urn:nbn:se:liu:diva-124676 